\title{
Understanding female genital mutilation/cutting abandonment in Egypt
}

\author{
Nada Wahba \\ Population Council \\ Hania El Banhawi \\ Amira El Ayouti
}

Follow this and additional works at: https://knowledgecommons.popcouncil.org/departments_sbsr-rh

Part of the Demography, Population, and Ecology Commons, Family, Life Course, and Society Commons, Gender and Sexuality Commons, International Public Health Commons, and the Medicine and Health Commons How does access to this work benefit you? Let us know!

\section{Recommended Citation}

Wahba, Nada, Hania El Banhawi, and Amira El Ayouti. 2020. "Understanding female genital mutilation/ cutting abandonment in Egypt," Evidence to End FGM/C: Research to Help Girls and Women Thrive. New York: Population Council. 


\section{Evidence to End FGM/C}

Research to Help Girls and Women Thrive

\section{UNDERSTANDING FEMALE GENITAL MUTILATION/CUTTING ABANDONMENT IN EGYPT}

February 2020 


\section{UNDERSTANDING FEMALE GENITAL MUTILATION/CUTTING ABANDONMENT IN EGYPT}

NADA WAHBA HANIA EL BANHAWI AMIRA EL AYOUTI

POPULATION COUNCIL 
Evidence to End FGM/C: Research to Help Girls and Women Thrive generates evidence to inform and influence investments, policies, and programmes for ending female genital mutilation/cutting in different contexts. Evidence to End FGM/C is led by the Population Council, Nairobi in partnership with the Africa Coordinating Centre for the Abandonment of Female Genital Mutilation/Cutting (ACCAF), Kenya; the Global Research and Advocacy Group (GRAG), Senegal; Population Council, Nigeria; Population Council, Egypt; Population Council, Ethiopia; MannionDaniels, Ltd. (MD); Population Reference Bureau (PRB); University of California, San Diego (Dr. Gerry Mackie); and University of Washington, Seattle (Prof. Bettina Shell-Duncan).

\section{POPULATION COUNCIL}

Ideas. Evidence. Impact.
The Population Council confronts critical health and development issues-from stopping the spread of HIV to improving reproductive health and ensuring that young people lead full and productive lives. Through biomedical, social science, and public health research in 50 countries, we work with our partners to deliver solutions that lead to more effective policies, programmes, and technologies that improve lives around the world. Established in 1952 and headquartered in New York, the Council is a nongovernmental, nonprofit organisation governed by an international board of trustees. www.popcouncil.org

Suggested Citation: Wahba, N., El Banhawi, H., and El Ayouti A. 2020. "Understanding female genital mutilation/cutting in Egypt." Evidence to End FGM/C: Research to Help Girls and Women Thrive. New York: Population Council.

This is a working paper and represents research in progress. This paper represents the opinions of the authors and is the product of professional research. This paper has not been peer reviewed, and this version may be updated with additional analyses in subsequent publications. Contact: [nwahba@popcouncil.org].

Please address any inquiries about the Evidence to End FGM/C programme consortium to:

Dr Jacinta Muteshi, Project Director, imuteshi@popcouncil.org

Funded by:

This document is an output from a programme funded by the UK Aid from the UK government for the benefit
of developing countries. However, the views expressed and information contained in it are not necessarily
those of, or endorsed by the UK government, which can accept no responsibility for such views or information 


\section{Contents}

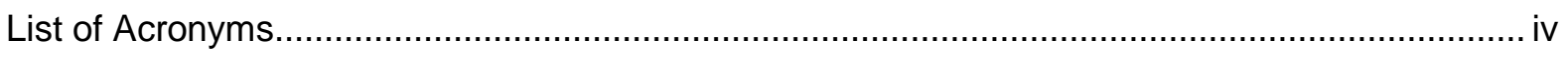

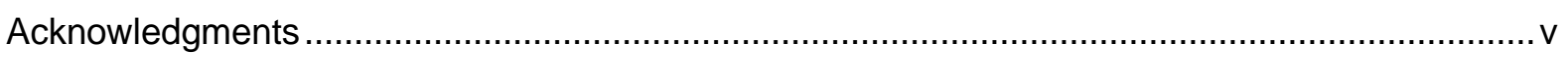

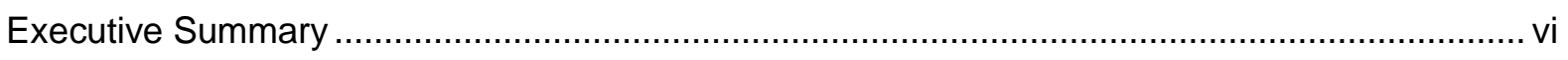

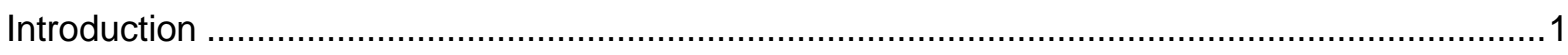

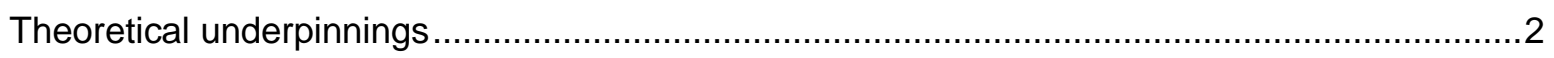

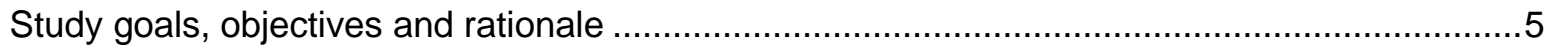

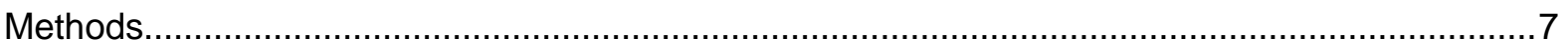

Study design

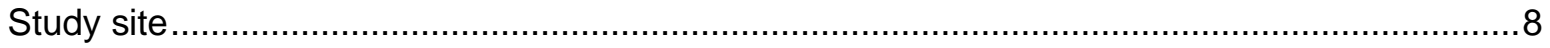

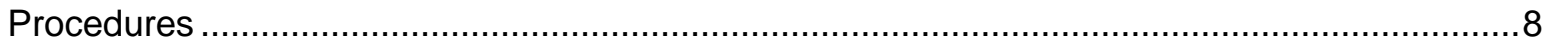

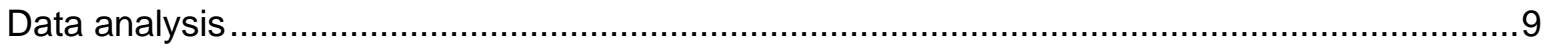

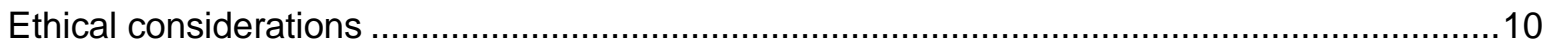

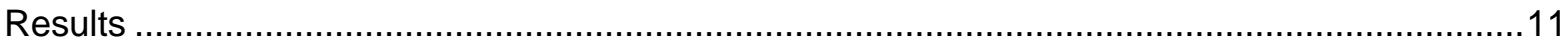

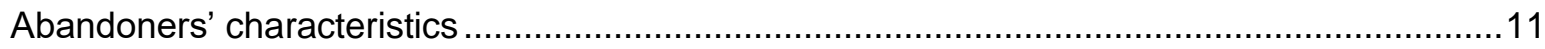

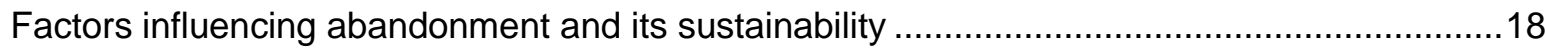

Challenges and tensions faced by abandoners within their families or communities and

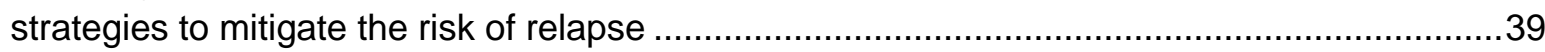

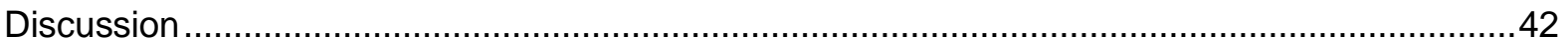

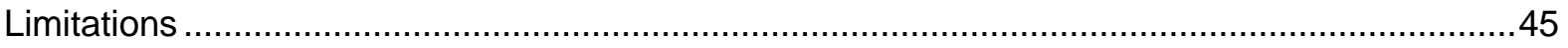

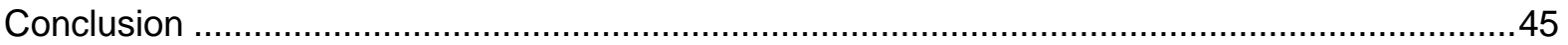

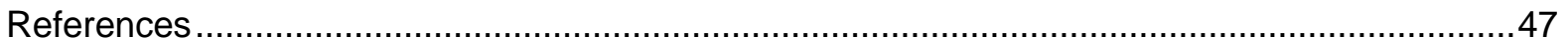

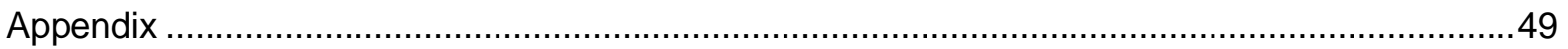

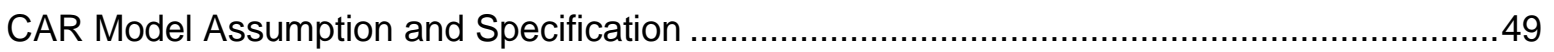




\section{List of Acronyms}

$\begin{array}{ll}\text { EDHS } & \text { Egyptian Demographic and Health Survey } \\ \text { EHIS } & \text { Egypt Health Issues Survey } \\ \text { FGD } & \text { Focus Group Discussion } \\ \text { FGM/C } & \text { Female Genital Mutilation/Cutting } \\ \text { IDI } & \text { In-Depth Interview } \\ \text { NGO } & \text { Non-Governmental Organisation } \\ \text { OR } & \text { Odds Ratio } \\ \text { PD } & \text { Positive Deviance } \\ \text { SYPE } & \text { Survey of Young People in Egypt }\end{array}$




\section{Acknowledgments}

This report was co-authored by Nada Wahba, Hania El Banhawi and Amira El Ayouti with the research technical and editorial support of Nahla Abdel-Tawab (Population Council) and Kathryn Yount (Emory University).

We would like to thank Chibuzor Nnanatu, Northumbria University for providing valuable technical support in conducting the spatial analysis. The authors of this report are grateful for the insightful comments and edits made by Jacinta Muteshi, Esther Lwanga, Caroline Kabiru, and Michelle Hindin (Population Council). We would also like to extend our thanks to the Project's Independent Consortium Advisory Group for their suggestions and the research consortium for their inputs.

Special thanks are due to our Egypt Advisory Group_Dr Abdel-Hameed Attia (Cairo University); Dr Amr Hassan (National Population Council); Dr Hossam Abbas (Ministry of Health and Population); Dr Khaled El Oteifi (Ministry of Health and Population); Dr Magdy Khaled (Independent Reproductive Health Consultant); Dr Nasser El Khouly (Consultant of Obstetrics and Gynecology). We are also sincerely grateful to our Steering Committee-Dr Dina Makram Ebeid (American University in Cairo); Ms Doaa Abdel Aal (Independent Researcher); Dr Hania El Sholkamy (American University in Cairo); Dr Laila Ahmed (UNICEF); Ms Lobna Darwish (Egyptian Initiative for Personal Rights); Ms Nana El Hariry (Ikhtyar African Feminist Collective); and Dr Randa Fakhr (NGOs Coalition against FGM/C). We express our gratitude for their valuable contributions during the conceptualisation of the study and the development of data collection instruments. 


\section{Executive Summary}

\section{Background}

Although the prevalence of female genital mutilation/cutting (FGM/C) in Egypt among married women aged 15 - 49 years is high (92\%) in the most recent (2014) Demographic and Health Survey (DHS), prevalence rates appear to be declining among younger cohorts of girls and women. Support for the discontinuation of the practice is also more widespread in younger generations, among females, and among those living in urban areas. Variations in attitudes towards FGM/C by education level, and wealth status are also documented.

While there have been numerous studies that have examined the reasons why people practise $\mathrm{FGM} / \mathrm{C}$, there have been few studies that examine the characteristics of the much smaller subset of individuals who have abandoned the practice. In this study, we sought to: examine the characteristics of abandoners and explore the geographic patterns of FGM/C abandonment; explore the benefits gained and challenges faced by abandoners within their families/communities; understand how families and individuals overcome social sanctions and mitigate against the risk of relapse.

\section{Methods}

We conducted a comparative, multi-site, mixed methods study comprising a secondary analysis of nationally representative quantitative data and primary qualitative research in Cairo, urban and rural Gharbeya (a Lower Egypt Governorate) and urban and rural Sohag (an Upper Egypt Governorate).

The primary objectives of the secondary analysis were to (1) examine the socio-economic and demographic characteristics of abandoners and (2) study the geographic patterns of $\mathrm{FGM} / \mathrm{C}$ abandonment. The secondary analysis utilised data from the 2014 Egypt DHS. We considered a woman an 'abandoner' if she had at least one daughter who was not circumcised and reported that she did not intend to cut her in the future. To assess the geographic variation and clustering of FGM/C abandonment in Egypt, in addition to the impact of socio-economic and demographic factors on the prevalence rates of abandoners, a two-level hierarchical spatial generalised mixed model was used. We analysed and modelled the geographic patterns of FGM/C abandonment and the effects of other individual-level factors using an additive semi-parametric mixed model that accounts for the spatial dependence between neighbouring areas using a conditional autoregressive (CAR) model.

The qualitative interviews explored the personal experiences and histories of young women and mothers who have abandoned FGM/C, as well as the challenges they faced, and the mitigation approaches that they used to avoid the risk of relapse. To capture possible geographic variability, qualitative data were collected in three governorates: Sohag, Cairo, and Gharbeya. In Sohag and Gharbeya, data were collected evenly in one rural and one urban site. We conducted eight focus group discussions (FGDs) with young women aged $18-24$ years $(n=76)$, twenty in-depth interviews (IDIs) with uncut young women aged $18-24$ years and 20 IDIs with mothers of uncut young women aged $18-24$ years.

\section{Results}

We observed a strong spatial dependence in the abandonment of the practice-although the strength of the dependence varied from one area to another. Results of the secondary analyses showed that women who were uncut, were eight times more likely than cut women to be abandoners. Christian women were also more likely than Muslims in the same areas to be 
abandoners. Mothers' education and wealth were also strongly associated with the likelihood of abandonment.

Results from the qualitative interviews showed that there was disparity in the meaning of abandonment. While some were against circumcision in all its forms, others did not associate medicalised circumcision with what is perceived as a traditional form of FGM/C historically performed by dayas (traditional circumcisers). For the latter group of women, abandoning the practice did not necessarily mean that they are against seeking a doctor's opinion on whether a girl "needs" to be circumcised.

Mothers who were convinced that they should not circumcise their daughters, usually did so out of a belief that they are protecting and preserving them from physical and psychological harm and sexual frigidity. Many mothers' personal experiences drove their decision to abandon - mentioning either their traumatic experience of the act of circumcision, the psychological burden they carried afterwards, and the lack of sexual satisfaction in their marriage. Awareness of the experiences of other family and community members also influenced some women's decision not to circumcise their daughters. While some participants seemed to be aware of the law against FGM/C, it was not the sole push factor for any of the participants to abandon.

Some participants reported that they had relapsed-meaning that they started circumcising their younger daughters after having not circumcised their oldest. Some of these participants noted that they were confused as to what exactly the harms or benefits of the practice were. Others relapsed because of pressure from the community.

Findings suggest that abandoners are often aware of traditional views that FGM/C has an impact on a woman's behaviour, though they may not personally adhere to these beliefs themselves. Thus, some abandoners are often highly aware of the critical eye of society's gaze. For some, $\mathrm{FGM} / \mathrm{C}$ was a thing of the past, associated with older, more traditional generations. The belief in the existence of many other abandoners also appeared to foster space and encouragement for FGM/C abandonment and discourage relapse.

\section{Discussion}

Results point to the importance of re-defining what exactly $\mathrm{FGM} / \mathrm{C}$ is, as it is apparent from the qualitative data collected that the meaning of abandonment of the practice is not uniform. It is important to recognise the dangers of the practice even when performed by a medical practitioner. More importantly, it is also crucial to start moving the narrative against FGM/C away from the medical harms of the practice to ensure the sustainability of abandonment efforts and start tackling the root causes of the issue-which is the belief that girls' and women's libido should be regulated.

While there seems to be some social status—or social utility-gained by abandoners in seeing and presenting themselves as more educated and progressive than those who circumcise, findings suggest that abandoners still face reputational and tangible costs. Addressing the beliefs around acceptable female behaviour, as well as the relationship between circumcision and behaviour, is important in changing communities' perception about the assumed benefits of circumcision, and thereby fostering less judgement, and lowering the reputational costs associated with abandonment. Moreover, interventions that aim to raise awareness, should build on mothers' own personal experiences, as this seems to be a strong deterrent against circumcision. Finally, it is important for programmes to address medicalised FGM/C as some people may believe there is a "need" for medicalised circumcision, a common belief, even for some who have already abandoned the practice in its traditional form. 


\section{Introduction}

According to the 2014 Egypt Demographic and Health Survey (EDHS), 92 percent of all Egyptian married women (ages 15-49 years) have been cut. As shown in Figure 1, levels of female genital mutilation/cutting $(\mathrm{FGM} / \mathrm{C})$ are high across the country, but lowest in frontier governorates, urban Lower Egypt, and urban governorates (i.e. Cairo). Female genital mutilation/cutting is mostly conducted as a rite of passage into female adulthood, a requirement for marriageability, and a method of curbing sexuality to ensure virginal purity before marriage and faithfulness after (WHO 2010).

\section{Figure 1. Percentage of women aged 15 - 49 years who have undergone FGM/C}

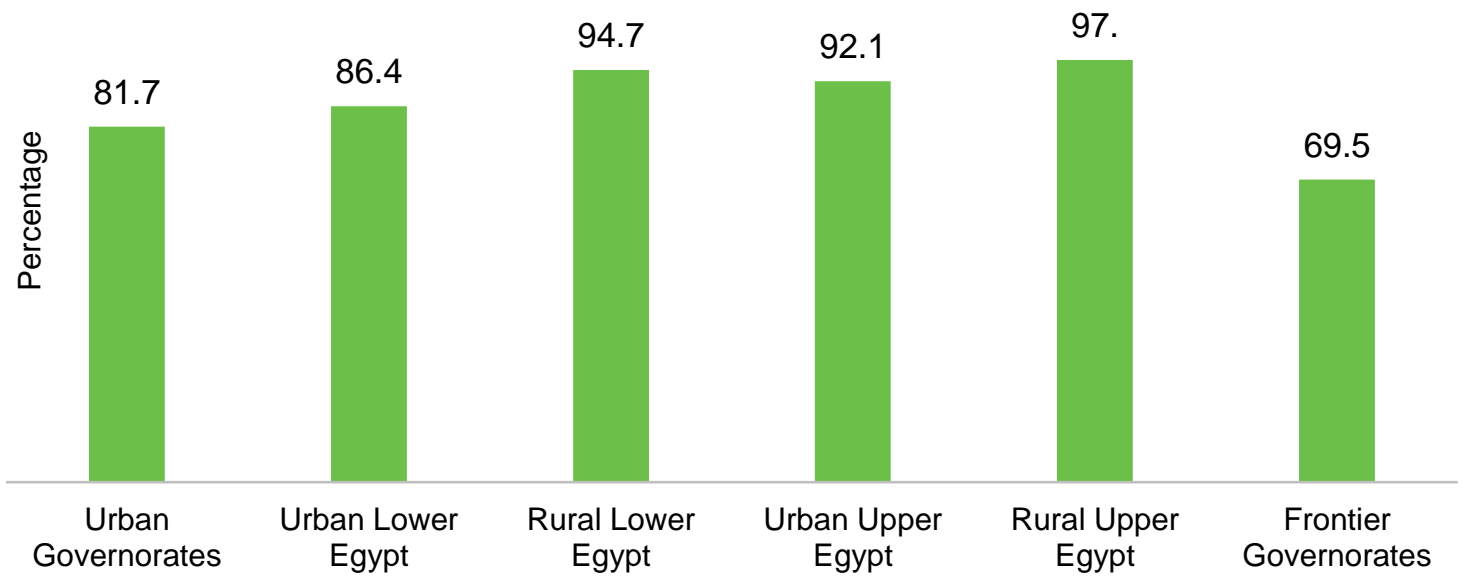

Source: EDHS, 2014

Data from the 2014 EDHS indicates a slight shift in practice amongst young women and girls. While still exceeding 80 percent, the prevalence of FGM/C among women younger than 25 years was lower than that among women aged $25-49$ years (90\%-95\%). Data from the 2014 Survey of Young People in Egypt (SYPE) also showed a decline within younger generations (73\% of girls aged $13-17$ years were cut compared to $88 \%$ of women aged $30-35$ years). In addition, a comparison of data from the 2008 and 2014 EDHS shows that the proportion of females aged 15 - 17 years who had been cut dropped by 13 percentage points between the two surveys (El-Zanaty and Way 2009; Ministry of Health and Population, et al. 2015a). Some women in this cohort who are not yet cut may be cut in the future. However, it is highly unlikely given that age 10 is the average age of FGM/C in Egypt and few Egyptian women are cut after the age of 15 years (Ministry of Health and Population, et al. 2015a).

The shifts in the prevalence of FGM/C mirror some changes in attitudes. The 2009 and 2014 Survey of Young People in Egypt (SYPE) found a slight decrease in the proportion of participants ages $15-29$ year who stated that FGM/C is necessary (64\% to 60.3\%) (Ismail, Abdel-Tawab and Sheira 2015). In both surveys, female participants were more likely than their male counterparts to support the abandonment of FGM/C. Similarly, the 2015 Egyptian Health Issues Survey (EHIS) revealed that 37 percent of female participants said FGM/C should be stopped compared to 28 percent of male participants (Ministry of Health and Population, El-Zanaty and Associates, and ICF International 2015b). The reasons behind the gender differences in attitudes remain unclear.

The pattern of variation of men's beliefs is, however, similar to that of women with regards to FGM/C abandonment. Support for the discontinuation of the practice is more widespread among 
urban than rural men and women. Among males and females aged $15-49$ years, those living in urban governorates are the most supportive of abandonment. For example, 52 percent of adults in the urban governorates think FGM/C should be abandoned compared to 31.5 percent in Lower Egypt, and 26.5 percent in Upper Egypt (Ministry of Health and Population, et al. 2015a). Variations in attitudes towards FGM/C by age, education level, and wealth status are also documented. In the 2015 EHIS (Ministry of Health and Population, et al. 2015b), participants younger than 34 years were more likely than older participants to support abandonment. Further, the proportion of men and women who supported abandonment increased with rising education and wealth. Men and women working for cash were more likely than those not working for cash to be supportive of abandonment. The reasons for the variations in attitudes towards FGM/C by region and sociodemographic characteristics are not clearly understood. Interrogation of the reasons for these variations is important for informing the targeting of interventions and documenting changes in the practice. It will facilitate the customisation of efforts for multiple target groups to ensure the effective delivery and receptiveness of the FGM/C abandonment messages.

Research shows that parents want what is best for their children (Ahmed et al, 2009). It is the most basic value that motivates parents to choose to practice or abandon FGM/C. Egypt has been witnessing slight shifts towards FGM/C abandonment across the past few years. It is worth noting that many campaigns and public declarations to encourage abandonment have taken place in Egypt, which may be considered a visible sign of progress. Substantial abandonment, however, is not guaranteed or in many cases sustained as there is evidence of relapse among some people who have previously publicly declared that they have abandoned the practice (Population Council, 2008). Research also shows that in Egypt families rely heavily on the opinion of medical doctors regarding whether to cut or not cut their daughters. With the high prevalence of medicalisation in Egypt where 74 percent of girls are cut by medical doctors, there is a widespread belief that medicalisation makes FGM/C less harmful and reduces the risk of fatality (Modrek \& Sieverding, 2016).

Several factors may influence a family's decision to change their behaviour. These factors may be external, such as exposure to mass media, targeted community activities, and laws and policies. In Egypt, for example, there is a national law against the practice that was introduced in 2008 with higher penalties instituted in 2016 (5 to 7-year prison sentence to those who perform the practice) (Ghattass et al, 2017). There is less literature however, investigating internal factors that can lead to abandonment. This study aims to contribute to a deeper understanding of both the internal and external motivations that can push individuals to abandon, as well as the challenges that can lead to relapse.

\section{Theoretical underpinnings}

While there are many theories that may explain the change in the decision-making regarding $\mathrm{FGM} / \mathrm{C}$, there is little documented in theoretical frameworks around the status of $\mathrm{FGM} / \mathrm{C}$ abandonment, the social sanctions/benefits associated with it, and methods of risk mitigation. According to social convention theory (Mackie 2000), the decision to practise or not practice $\mathrm{FGM} / \mathrm{C}$ is not made by one individual or family. It is rather an interdependent decision that is mutually beneficial to everyone in a relevant social group and complies with the prevalent social rule. Mackie (2000) maintained that FGM/C was locked in place as a marriage convention and that it was in the best interest of everyone in the reference group to comply based on expectations. According to the theory, the practise of FGM/C is sustained because it is seen as necessary for a proper marriage.

Social convention theory has been contested by scholars such as Cloward (2016), who argues that some individuals are still capable of defecting unilaterally from the status quo, using various 
exit options. She explains that a defection of what she refers to as a social norm rather than a social convention is commonly attributed with a social cost. That social cost may vary across norms, individuals, or over time. In the case of $F G M / C$, the cost of abandonment is very high in most practising communities. Thus, individuals may need to have certain characteristics/exit options that would offset this high cost. The characteristics and exit options may be an elite social status or the rise of highly visible abandoners of the practice or others that would allow an early defector to be insensitive to the social cost.

Cloward (2016) refers to the net social costs and benefits experienced by a given individual for a given action at a given moment in time as the social utility. She then refers to intrinsic utility, a term used by Kuran (1995), to describe the benefit from the alignment of an individual's actions with one's real attitudes and preferences. Social utility and intrinsic utility must be balanced against each other. Kuran also added expressive utility to his framework. Expressive utility is the benefit driven from an individual's tolerance to express his/her real private views to the public rather than falsifying it. The sum of the three utilities is called the total utility that an individual derives from a given public action. If an individual is indifferent about two public actions, the total utility of both actions is equal; this indifference point is called the threshold. It is the individual's threshold relative to actual public behaviour that determines the individual's action. Figure 2 illustrates Cloward's Primary Behaviour and Social Costs Framework.

Figure 2. Primary behaviour and social costs framework

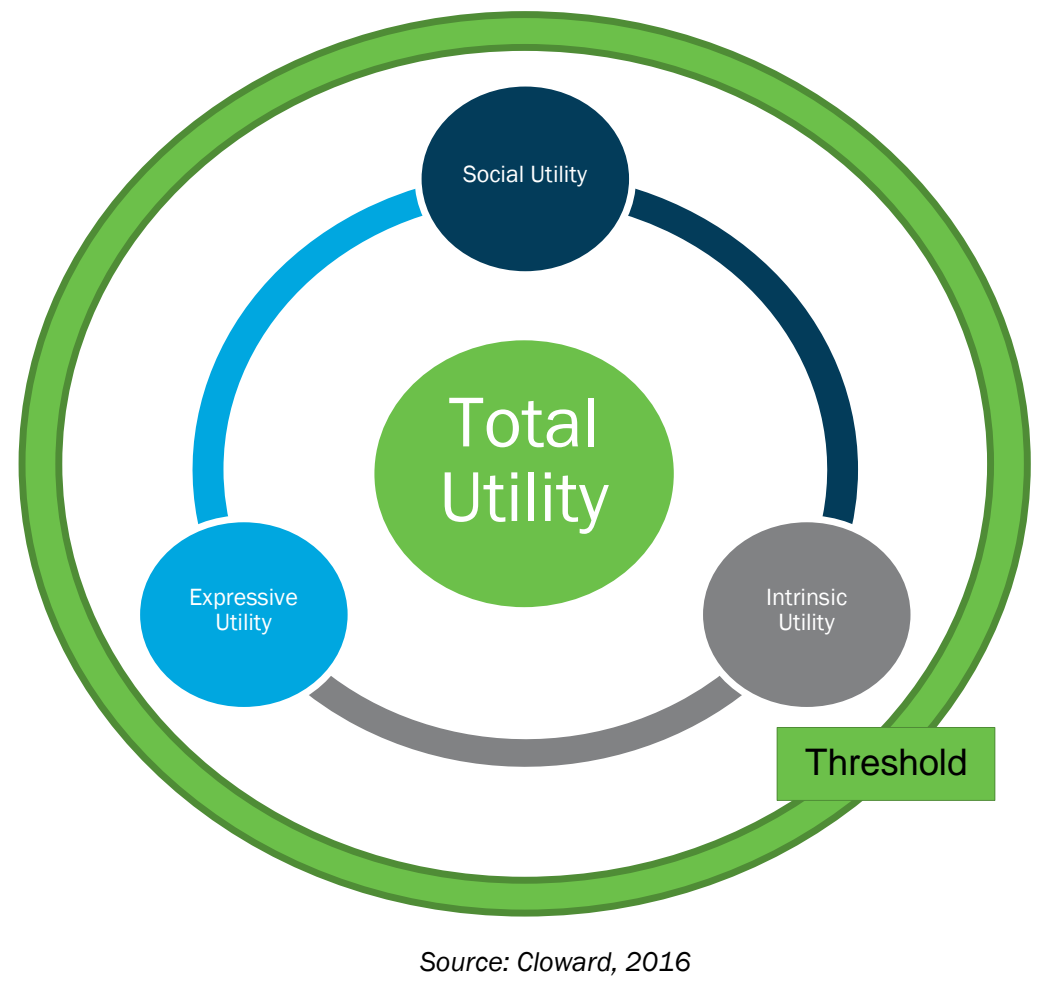

To defect from a dominant social norm, individuals need to reconcile their own attitudes/preferences and the attitudes/preferences of the community to which they belong. With a deeply rooted social norm like FGM/C, the social costs of abandonment may create a significant gap between public preferences and private preferences. Whether this gap can be overcome depends on the individual's tolerance to preference falsification (lower expressive utility), the strength of their views, and the extent to which social costs can be mitigated. 
As more people defect from a social norm, individual thresholds drop, and additional defections become easier. Late defectors are less likely to experience social sanctions or to be excluded from the marriage market. Cloward (2016) believes that the daughters of norm change leaders can end up providing a kind of demonstration effect by showing that uncut women can lead successful lives. These women can serve as flesh-and-blood role models for future families thinking about abandoning the social norms and their existence is likely to be more reassuring than activists' promises.

Going back to the initial view of social convention theory, it has also been contested because it fails to recognise that there are social, moral, and religious factors that may have contributed to holding the practice in place. These factors may also contribute to holding the abandonment status in place and playing a significant role within the intrinsic and social utility as private and public preferences may be guided by them as well. Therefore, Mackie and LeJeune (2009) introduced the harmonisation of norms-including social, moral, legal, and religious norms-concept as the ultimate factor sustaining the practice and its abandonment. Unlike a social convention, a social norm is a practice that is enforced by informal social sanctions. That is, regardless of the individual's interest, there is a societal expectation to follow a social rule. In addition to social norms, Mackie and LeJeune (2009) define moral norms, religious norms, and legal norms. Moral norms are upheld by internalised values that are enforced by an individual based on what they believe is "right" or "wrong," independent of the expectations of others. For example, an individual's compliance with FGM/C may be associated with positive feelings of being a "good person" while non-compliance can evoke negative feelings of guilt. Religious norms are dictated by the fear of God. Obeying these norms is done out of fear of deity and obeying God's rules. In the case of FGM/C, many Muslims view it as Sunna - a normative moral law based on Islamic teachings. Legal norms are formally stated by the law such as imprisonment in the event a girl is cut by a doctor, midwife, or birth attendant.

Abandonment of $\mathrm{FGM} / \mathrm{C}$ is also said to be achieved through organised diffusion, involving participants sharing information, persuasion, and debate spread through existing familial and social networks. The diffusion of innovation theory thus offers further theoretical insight into the mechanisms by which one might establish change at a community level. Diffusion of innovation theory describes the characteristics of the people who might adopt an unconventional $/$ new idea, such as FGM/C abandonment, and characteristics of the innovation itself as relevant to individual decision-making and broader adoption in the community (Rogers, 1962). Adopters are classified as innovators, early adopters, early majority, later majority, and laggards, depending on their relevant point of uptake of an innovation (Figure 3). These categories of adopters have been found to have different characteristics (e.g. innovators are risk-takers while the late majority are sceptical) that determine their desire to engage with an innovation and communicate with others about it. What is problematic in terms of ending FGM/C is determining the characteristics and motivation to defect that typify innovators and early adopters and how can such families be identified and supported. This is where the total utility framework may be integrated to further understand how the various classifications of adopters are typified. 


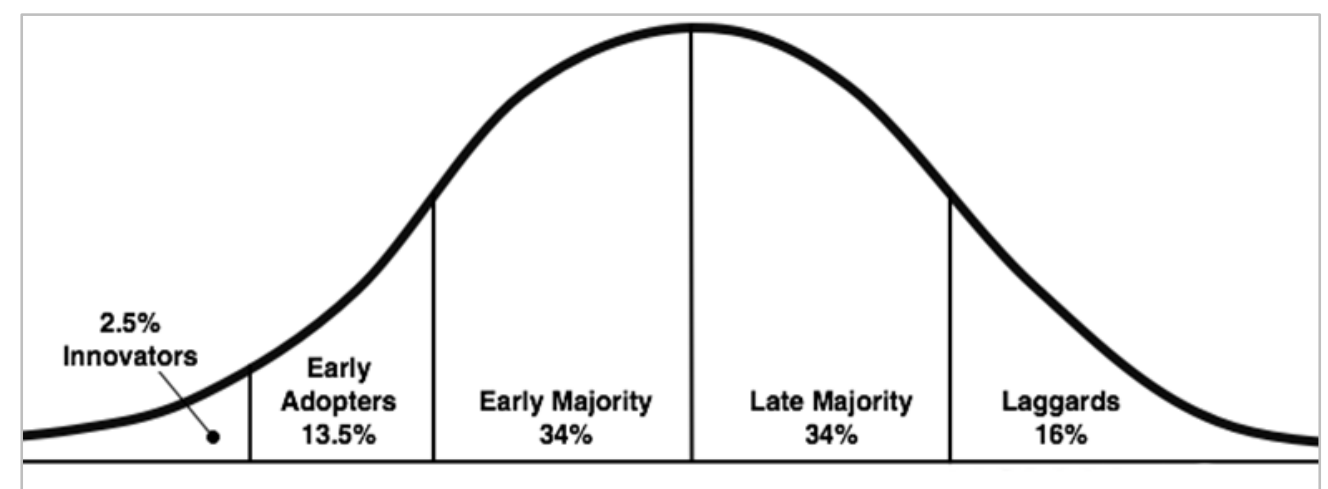

Source: http://sphweb.bumc.bu.edu/otlt/MPH-Modules/SB/BehavioralChangeTheories/BehavioralChangeTheories4.html

In high prevalence settings like Egypt, abandonment is considered a form of positive deviance (PD) by which FGM/C abandoners are individuals who have solved a problem (i.e., FGM/C) and would thus spread their unique solutions to others within their local community (Bullen 2012). While there have been calls for PD to become a standard tool in behavioural change communication, there has been little research on the approach. One of the few studies on PD in FGM/C abandonment was conducted in Egypt in 2008. The study, which evaluated the effectiveness of the approach in the FGM/C Abandonment Programme, showed that an increased number of girls have been saved from undergoing FGM/C after the programme (Population Council 2008). The current study builds on this research and aimed to contribute to knowledge of PD.

To create a comprehensive framework that would encompass the potential factors and reflect an accurate picture of the experiences that abandoners go through, we integrated the harmonisation of norms concept and primary behaviour/social cost framework. We used this framework as well as the diffusion of innovation theory to understand current abandoners in Egypt, what kind of benefits/sanctions they receive because of their abandonment status, and how they mitigate the risk of relapse.

\section{Study goals, objectives and rationale}

\section{Study goal}

The overall aim of this study was to understand the characteristics of abandoners, the challenges they have faced in abandoning $F G M / C$, and factors which may have helped them maintain their abandonment position. The study results are expected to contribute to interventions that encourage people to defect from social norms that underpin the practice and eventually achieve full abandonment of the practice. Abandoners are defined in this study as individuals or families that are known among their peers, neighbours, and families not to have cut at least one of their daughters, preferably the youngest. These individuals or families may have publicly announced their abandonment or are secretively known to have done so. Including both those who have publicly announced their abandonment and those who secretly abandon the practice enabled us to examine differences in challenges experienced by the public and secretive abandoners.

The abandoning family unit included the father, mother, uncut daughter, and her spouse (if the uncut daughter was married). Daughters' spouses were included in the unit as they may have contributed or were subjected to challenges (or vice versa) for being married to an uncut woman. Abandoners also included daughters (and their families) who were uncut based on advice from a doctor following examination. 


\section{The study objectives}

- To examine the characteristics of abandoners (i.e. individual, couple, household, and community) and explore the geographic patterns of FGM/C abandonment;

- To explore the benefits gained and challenges faced by abandoners within their families/communities;

- To understand how families and individuals overcome social sanctions and mitigate against the risk of relapse.

\section{Research questions}

- What are the characteristics of abandoners and where are they located? (i.e. individual, couple, household, and community)

- What kind of challenges and tension do abandoners face within their families / communities and how do they mitigate the risk of relapse?

- What are the factors influencing abandonment and its sustainability?

- What are the key reasons behind relapse in FGM/C practice amongst abandoners?

\section{Rationale}

The decision to undergo FGM/C in Egypt is mainly driven by prevailing social norms and is influenced by families, peer groups, and community (Naguib 2010). Challenging these social norms and choosing to abandon the practice may be associated with high stakes. However, the characteristics of FGM/C abandoners, their experiences with abandonment, and how they managed to sustain their status are not well understood. Although research has focused much attention on understanding why FGM/C is practised, little is known about why some families have stopped practising FGM/C. Evidence from existing studies particularly concentrate on $\mathrm{FGM} / \mathrm{C}$ practitioners with emphasis on the how, why, where, and by whom $\mathrm{FGM} / \mathrm{C}$ is practised (Behrendt 2005). However, as highlighted by Lionello (2015) in her study on the experience of abandonment in Sierra Leone, the stories of abandoning individuals, families, and communities often go unreported. In countries like Egypt where $\mathrm{FGM} / \mathrm{C}$ is a social norm and where many families adhere to the practice, understanding the stories of individuals, families, and communities who go against the predominant norms may strengthen the work to end FGM/C. Understanding these individual and family experiences may be useful in informing the design of programmes to enable abandoners to develop resilience and to cope more effectively with the stresses and pressures stemming from their decisions.

This study explored the benefits gained and challenges faced by individuals and families that commit to abandoning FGM/C and communicating their choice to their social network or publicly. The decision-making process to abandon FGM/C is explored in a separate study (Galal, Keller, Abou Hussein, and Wahba forthcoming). According to Cloward (2016), the more salient the social norm, the greater the potential social sanctions and the higher the barrier to defection. Individuals who move first to abandon a social norm are more likely to face social sanctions than individuals who abandon it later. However, early defectors may overestimate the costs of abandonment because of limited exposure and lack of adequate information. While the logic of social norms underlying $\mathrm{FGM} / \mathrm{C}$ tends to predict severe consequences for women who do not undergo it, these consequences have not been researched based on real-life examples. The sanctions are currently only assumptions that have not been validated in the available literature. Also, there is no account of any rewards that may have been attributed to being uncut. This study adds to the sparse literature on abandonment by documenting the benefits and challenges associated with abandonment. 


\section{Methods}

\section{Study design}

We conducted a comparative, multi-site, mixed methods study comprising a secondary analysis of nationally representative quantitative data and primary qualitative research in Cairo, urban and rural Gharbeya (a Lower Egypt Governorate) and urban and rural Sohag (an Upper Egypt Governorate) (Figure 4).

Figure 4. Map of Egypt's governorates

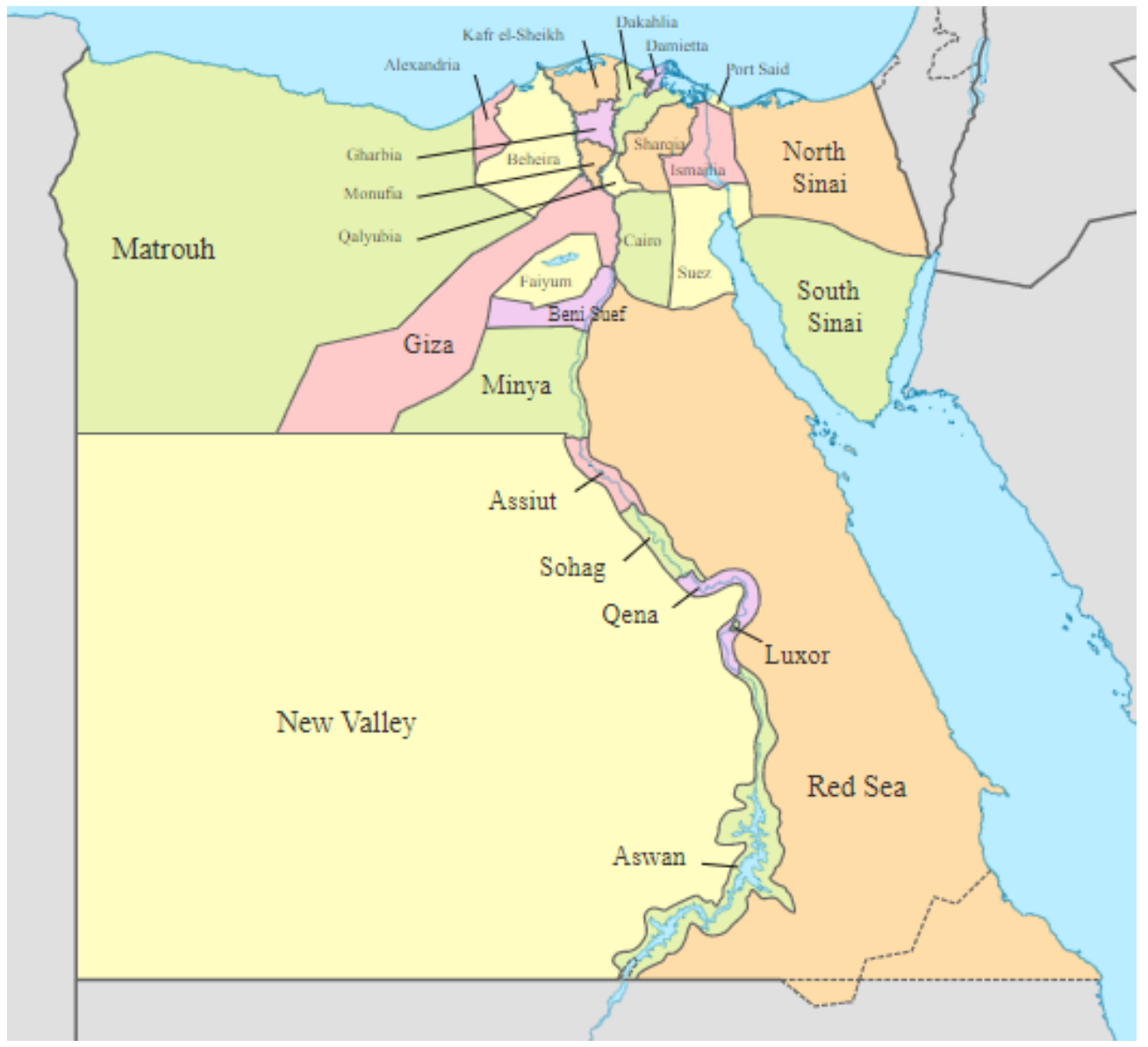

Source: https://commons.wikimedia.org/wiki/File:Egypt, administrative divisions - Nmbrs - monochrome.svg TUBS / CC BY-SA (https://creativecommons.org/licenses/by-sa/3.0)

Note: Gharbia is also spelled as Gharbeya

The objectives of the secondary analysis were to (1) examine the socio-economic and demographic characteristics of abandoners and (2) study the geographic patterns of $\mathrm{FGM} / \mathrm{C}$ abandonment, The secondary analysis utilised data from the 2014 EDHS. The EDHS is a nationally representative survey of health and welfare indicators pertaining to ever-married women ages 15 to 49 years and their households. In 2014, data were collected from a sample of nearly 30,000 households and more than 21,000 women.

The qualitative interviews explored the personal experiences and histories of young women who have abandoned FGM/C, as well as the challenges they faced, and the mitigation approaches that they used to avoid the risk of relapse. Interviews with mothers of uncut young women similarly explored the personal experiences and histories of mothers who have abandoned $\mathrm{FGM} / \mathrm{C}$, as well as the challenges faced by families and the mitigation approaches that they used to avoid the risk of relapse. The qualitative component employed a grounded theory design, which is a qualitative 
research design in which theory is formed based on the gathered data, as opposed to having data gathered after having formed a theory (Strauss \& Corbin, 1990). The theory is grounded in the data, hence the term 'grounded theory.'

\section{Study site}

To capture possible geographic variability, qualitative data were collected in three governorates: Sohag, Cairo, and Gharbeya. Cairo and Gharbeya are governorates in Lower Egypt, while Sohag is a governorate in Upper Egypt. In Sohag and Gharbeya, data were collected evenly in one rural and one urban site.

\section{Procedures}

Data were collected between April 2019 and August 2019 using focus group discussions (FGDs) and in-depth interviews (IDIs). The main purpose of the FGDs was to identify uncut young women aged $18-24$ years who are comfortable talking about abandonment of FGM/C. Participants were asked if they know any abandoners, without providing names. The data collectors individually approached any young women who publicly declared in the FGDs that they are uncut and invited them (after the FGD) to participate in the IDIs. These women also served as seed participants to identify or recommend other uncut women through snowball sampling. The decision to limit the sample of young women to age 18 and older was based on the low chances of these women being cut in the future.

Prior to fieldwork, ten data collectors with experience conducting FGDs and IDIs were recruited as potential interviewers. Data collectors then participated in a training workshop on the research topic, study instruments, research ethics, maintaining confidentiality and effective interviewing, including probing in a non-judgemental and non-directive manner. During the workshop, interviewers performed mock interviews and received feedback on their performance. The study tools were also pretested in Cairo and revised during the workshop. Data were collected by seven of the trained data collectors.

We collaborated with local non-governmental organisations (NGOs) that have worked in the field of $\mathrm{FGM} / \mathrm{C}$ abandonment in the three governorates to identify participants for the discussions and interviews (when the FDGs were unable to identify a sufficient pool of young women who were uncut). The IDIs and FGDs were conducted in NGO premises in spaces that provided auditory privacy. Interviews were conducted and transcribed in Arabic. To guarantee a high quality of data, the project team regularly monitored data collection activities and transcription and routinely met with data collectors to discuss their experiences and address any challenges.

We conducted eight FGDs with young women aged $18-24$ years. Each FGD had $8-11$ participants. Two FGDs took place in Cairo, one in urban Sohag, two in rural Sohag, one in urban Gharbeya, and two in rural Gharbeya. The discussions were audiotaped and lasted between 60 and 90 minutes. The FGDs were guided by a semi-structured discussion guide and focused on participants' knowledge about FGM/C and its practice in the community.

A total of 20 IDIs (4 per study site) with uncut young women (both married and unmarried) and 20 IDIs with mothers of uncut young women were conducted (Table 1). Approval to conduct interviews with parents was sought from the young women to avoid any risk of family retribution. Mothers were only interviewed after the uncut young woman agreed that she could be reached. Participants were identified and recruited through the FGDs and through the NGOs when the FGD sample did not yield saturation. IDIs were audiotaped and lasted between 25 and 50 minutes and were guided by a semi-structured discussion guide. Table 1 summarises the number of participants in each qualitative data collection activity. 
Table 1. Qualitative interview participants by data collection activity

\begin{tabular}{|l|l|l|l|l|l|}
\hline \multirow{2}{*}{ Data collection activity } & \multicolumn{4}{l}{ Number of participants } \\
\cline { 2 - 7 } & Cairo & $\begin{array}{l}\text { Gharbeya } \\
\text { (Rural) }\end{array}$ & $\begin{array}{l}\text { Gharbeya } \\
\text { (Urban) }\end{array}$ & $\begin{array}{l}\text { Sohag } \\
\text { (Rural) }\end{array}$ & $\begin{array}{l}\text { Sohag } \\
\text { (Urban) }\end{array}$ \\
\hline $\begin{array}{l}\text { Focus group discussions (FGDs) } \\
\text { with young women aged 18-24 } \\
\text { years }\end{array}$ & $2(n=20)$ & $2(n=20)$ & $1(n=8)$ & $2(n=20)$ & $1(n=8)$ \\
\hline $\begin{array}{l}\text { IDls with uncut young women aged } \\
18-24 \text { years }\end{array}$ & $n=4$ & $n=4$ & $n=4$ & $n=4$ & $n=4$ \\
\hline $\begin{array}{l}\text { IDIs with mothers of uncut young } \\
\text { women aged 18 - 24 years }\end{array}$ & $n=4$ & $n=4$ & $n=4$ & $n=4$ & $n=4$ \\
\hline
\end{tabular}

\section{Data analysis}

\section{Secondary quantitative data}

To examine the socio-economic and demographic characteristics of abandoners and study the geographic patterns of FGM/C abandonment, we analysed data from the $2014 \mathrm{EDHS}$. The sample included 21762 ever married women aged $15-49$ years who were interviewed about their FGM/C status and that of their daughters. Of these women, 15323 had at least one daughter alive and 14191 (14118 weighted) reported information on the circumcision of their daughter(s). The mean age of the women in the sample was 34 years; $65 \%$ were living in rural areas and $96 \%$ were Muslims. Nearly $25 \%$ of the women reported no formal education while $52 \%$ had completed secondary or higher education. We considered a woman an 'abandoner' if she had at least one daughter who was not circumcised and reported that she did not intend to cut her in the future. Abandoners comprised about $29 \%$ of all mothers aged $15-49$ years with at least one daughter alive and who reported on their daughters FGM/C status and their future FGM/C intentions (4035 of 14118).

In the first step of the analysis, we examined the prevalence rates of abandoners by some selected characteristics of the participants and their geographic or spatial locations. To examine the spatial distribution of FGM/C abandoners in Egypt, we calculated the prevalence rate of abandoners in each governorate of Egypt. These prevalence rates were then projected on Egypt's map to visualise the geographic distribution of abandoners. To quantify the presence of spatial autocorrelation in the prevalence rates of women who had abandoned FGM/C across Egypt governorates, we computed the Moran's I statistic (Moran, 1950). The Moran's I statistic is a measure of overall spatial autocorrelation, with values ranging between -1 and 1 . A negative value implies negative spatial autocorrelation; whereas a positive value indicates positive spatial autocorrelation. To test the significance of Moran's I, we conducted a permutation test (based on 10,000 random permutations of the data). The permutation test has the null hypothesis of no spatial autocorrelation (independence in space) and an alternative hypothesis of positive spatial autocorrelation. Positive spatial autocorrelation implies a clustering of similar values together in a map.

The statistical significances of bivariate associations between potential socio-demographic factors and the prevalence of FGM/C abandoners were explored by using Chi-square (Pearson, 2009) and Mann-Whitney U (Mann and Whitney, 1947) tests, as appropriate. Chi-square test was used for categorical factors and Mann-Whitney $U$ test was used for comparing continuous factors such as the woman's age between 2 groups. To assess the geographic variation and clustering of 
FGM/C abandonment in Egypt, in addition to the impact of socio-economic and demographic factors on the prevalence rates of abandoners, a two-level hierarchical spatial generalised mixed model was used. This class of hierarchical models was previously used to study the prevalence rates of FGM/C among women and daughters in Nigeria (Kandala et al.,2009) and Kenya (Achia, 2014). As the response variable was binary, where 0 denotes a non-abandoner and 1 denotes an abandoner, a logistic regression model was used, where the standard measure of effect is the odds ratio $(\mathrm{OR})$. The socio-economic factors included in the model were: mother's education, place of residence, religion, wealth, work status and age, in addition to the mother's own FGM/C status. Apart from age, which is a continuous variable, all the explanatory variables in the model were categorical variables. Reference categories were those living in a rural area, Muslim, illiterate (no education), from the poorest wealth quintile, not working, and who had undergone FGM/C. The model used also allows for non-linear effects of the age on FGM/C abandonment. Note that the model does not accept missing values in the covariates; and hence the model is applied only to 13037 women, of whom 4207 were abandoners, after the exclusion of missing observations.

We were also interested in analysing and modelling geographic patterns for FGM/C abandonment. The geographic patterns of FGM/C abandonment and the effects of other individual-level factors were examined using an additive semi-parametric mixed model that accounts for the spatial dependence between neighbouring small administrative areas using a conditional auto-regressive (CAR) model assuming that areas close to each other are more similar than areas far apart (MacNab, 2003). Such CAR model is a type of Markov random field (Lee, 2011). More details about the model are provided in the Appendix.

\section{Qualitative data}

Audio files and notes from the FGDs and IDIs were transcribed in Arabic in Microsoft Word. The purpose of the FGDs was largely to identify the IDI sample, and thus data analysis was limited to the IDIs. Data analysis of the IDIs was performed using grounded theory methodology (Glaser \& Strauss 1967). The Arabic transcripts were read repeatedly, and the raw data were coded thematically using Dedoose software package.

Codes and labels were attached to portions of the text related to a specific theme, leading to a set of descriptive themes and sub-themes for each transcript. A pre-set list of initial codes was developed based on the literature review and interview questions and was tested on a sample of transcripts. Subsequent inductive, exploratory analysis allowed for the emergence of additional codes from the data. The codes were confirmed, modified, discarded or regrouped during the ongoing analysis by re-examination of earlier data and considerations of subsequent data collected. The final codebook consisted of 17 themes and 45 codes and was used systematically to apply codes to text. Excerpt memos were recorded to suggest new interpretations and connections to other data. This technique allowed for the transcendent interpretation of the coded data and enabled the revelation of the richness, complexities and contradictions of the issue of FGM/C abandonment.

\section{Ethical considerations}

Ethical permission to conduct the study was provided by the Population Council's Institutional Review Board (IRB) and a local IRB in Egypt. Key researchers and practitioners in Egypt were invited to participate in the local IRB meeting. The project, its objectives as well as its methodology was presented in the meeting for feedback. The local IRB also reviewed the FGD and IDI guides and provided recommendations on the flow of questions and their wording. The guides were subsequently revised taking into account the IRBs' feedback. 
Participants in the FGDs and interviews were informed about the objective of the study and how their confidentiality would be protected. Whenever possible, different data collectors were used for different family members to ensure none of the data collectors knew what other family members had said. Data collectors were trained to maintain confidentiality and to handle sensitive issues appropriately. Access to the recorded digital tapes was restricted to the research team. All participants were assured that their participation in the study was completely voluntary and that they could withdraw at any point in the study. Informed consent and permission for digital recording were obtained.

\section{Results}

\section{Abandoners' characteristics}

Table 2 presents the distribution of ever-married women aged $15-49$ years who were categorised as abandoners by their demographic and socio-economic characteristics. The table shows that a greater proportion of abandoners than non-abandoners were living in urban areas $(56 \%$ versus $26 \%$, respectively). The results suggest that the likelihood that a woman had abandoned $\mathrm{FGM} / \mathrm{C}$ increased with her education level and age. A greater proportion of abandoners than nonabandoners belonged to households in the wealthiest quintile (37\% versus $11 \%$ ).

Table 2. Percentage of abandoners among ever-married women aged $15-49$ years by sociodemographic characteristics, EDHS 2014

\begin{tabular}{lcccc}
\hline Characteristics & \multicolumn{3}{c}{ Mothers abandoning FGM, $\mathbf{n}(\%)$} \\
& Yes & No & P-value \\
\hline Age & & & \\
$15-19$ & $29(0.7)$ & $140(1.4)$ & $<0.001$ \\
$20-24$ & $322(8.0)$ & $1145(11.4)$ & \\
$25-29$ & $825(20.4)$ & $2259(22.4)$ & \\
$30-34$ & $886(22.0)$ & $2230(22.1)$ & \\
$35-39$ & $847(21.0)$ & $1973(19.6)$ & \\
$40-44$ & $649(16.1)$ & $1394(13.8)$ & \\
$45-49$ & $477(11.8)$ & $942(9.3)$ & \\
Residence & & & \\
$\quad$ Urban & $2263(56.1)$ & $2657(26.4)$ & $<0.001$ \\
Rural & $1772(43.9)$ & $7426(73.6)$ & \\
& & & \\
Religion & & & & \\
$\quad$ Muslim & $3640(90.2)$ & $9957(98.8)$ & $<0.001$ \\
$\quad$ Not Muslim & $395(9.8)$ & $122(1.2)$ & \\
Education & & & \\
$\quad$ No education & $558(13.8)$ & $2935(29.1)$ & $<0.001$ \\
Some primary & $147(3.6)$ & $737(7.3)$ & \\
Primary complete/ some secondary & $563(14.0)$ & $1803(17.9)$ & \\
Secondary complete/ higher & $2767(68.6)$ & $4608(45.7)$ &
\end{tabular}




\begin{tabular}{lccc}
\hline Characteristics & \multicolumn{3}{c}{ Mothers abandoning FGM, n (\%) } \\
& Yes & No & P-value \\
\hline Wealth quintile & & & \\
$\quad$ Lowest & $346(8.6)$ & $2300(22.8)$ & $<0.001$ \\
Second & $505(12.5)$ & $2349(23.3)$ & \\
Middle & $691(17.1)$ & $2396(23.8)$ & \\
Fourth & $999(24.8)$ & $1896(18.8)$ & \\
$\quad$ Highest & $1493(37.0)$ & $1141(11.3)$ & \\
Work Status & & & \\
$\quad$ Working for Cash & $748(18.5)$ & $1258(12.5)$ & $<0.001$ \\
$\quad$ Not Working & $3286(81.5)$ & $8825(87.5)$ & \\
Total & $4035(28.6)$ & $10083(71.4)$ & \\
\hline
\end{tabular}

\section{Spatial distribution of FGM/C abandoners}

Figure 5 shows the proportion of women who were categorised as abandoners across the governorates of Egypt. There was a higher prevalence of abandoners in Lower Egypt relative to Upper Egypt. However, the aggregated governorate prevalence concealed important variation in the prevalence of abandoners at lower scales within the governorates (see Figure 6). For example, the overall prevalence of abandoners in Cairo was 50 percent but this rate varied from 14 percent (in Al-Darb Lahmar) to 100 percent (in Al-Maadi) within Cairo at the Kism level (that is, the second level of administrative unit in each governorate; rural areas are divided into markaz, whereas urban areas are divided into kism).

Figure 5. Map of the raw prevalence of women aged $15-49$ years who have abandoned FGM/C in Egypt governorates

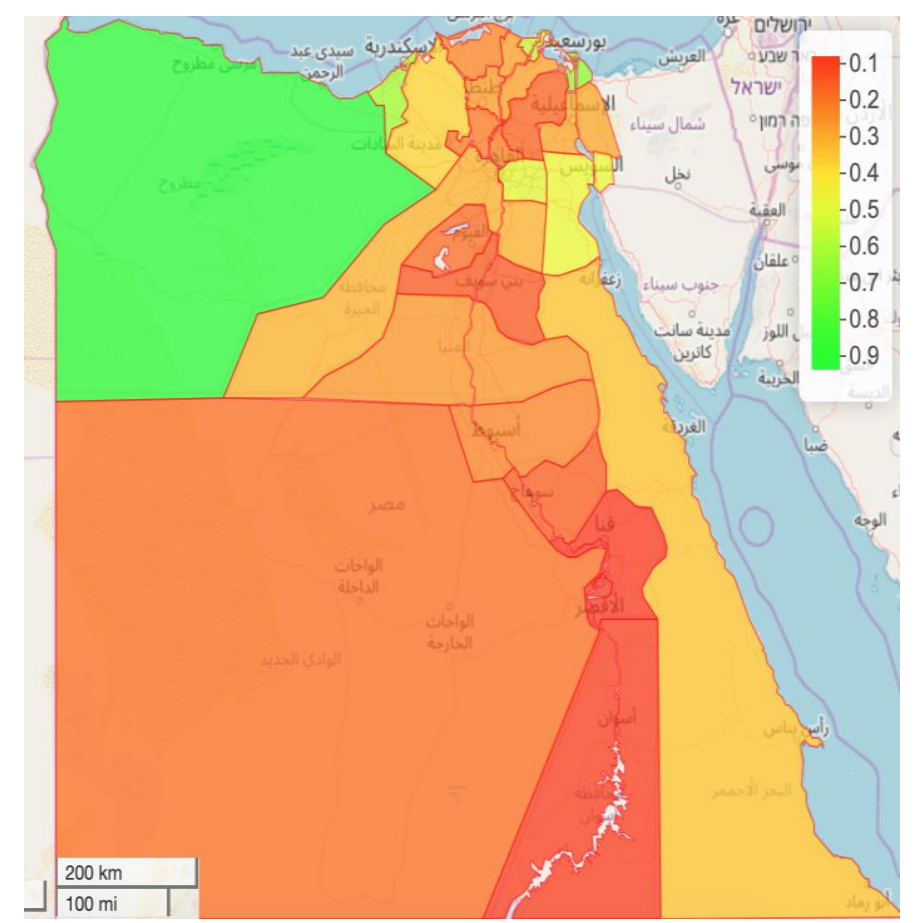


The Moran's I statistic resulted in a value of 0.18 and a $p$-value of 0.04 , which suggests a weak positive spatial autocorrelation, in the sense that nearby governorates do not necessarily have similar prevalence of abandoners. This result likely stems from the large variability in the characteristics of individuals within each governorate, which in turn makes the proportion of abandoners vary substantially from one governorate to another. In contrast, the spatial dependence in the prevalence of abandoners across the small administrative areas ( $\mathrm{kism} / \mathrm{markaz}$ ) within Egypt governorates estimated by Moran's I statistic is 0.52 with a p-value $<0.0001$, suggesting a substantial positive spatial autocorrelation. This result highlights the essential role of considering the small-scale variations attributed to the administrative subdivisions within governorates for a better estimation of the geographic distribution of FGM/C abandonment across Egypt. Although the kism or markaz is still a large unit, disaggregation to this level represents an advancement over the use of governorate and national averages.

\section{Figure 6. Map of the raw prevalence rates of women aged $15-49$ years who have abandoned} $\mathrm{FGM} / \mathrm{C}$ in the administrative subdivisions (kism/markaz) of Egypt governorates.
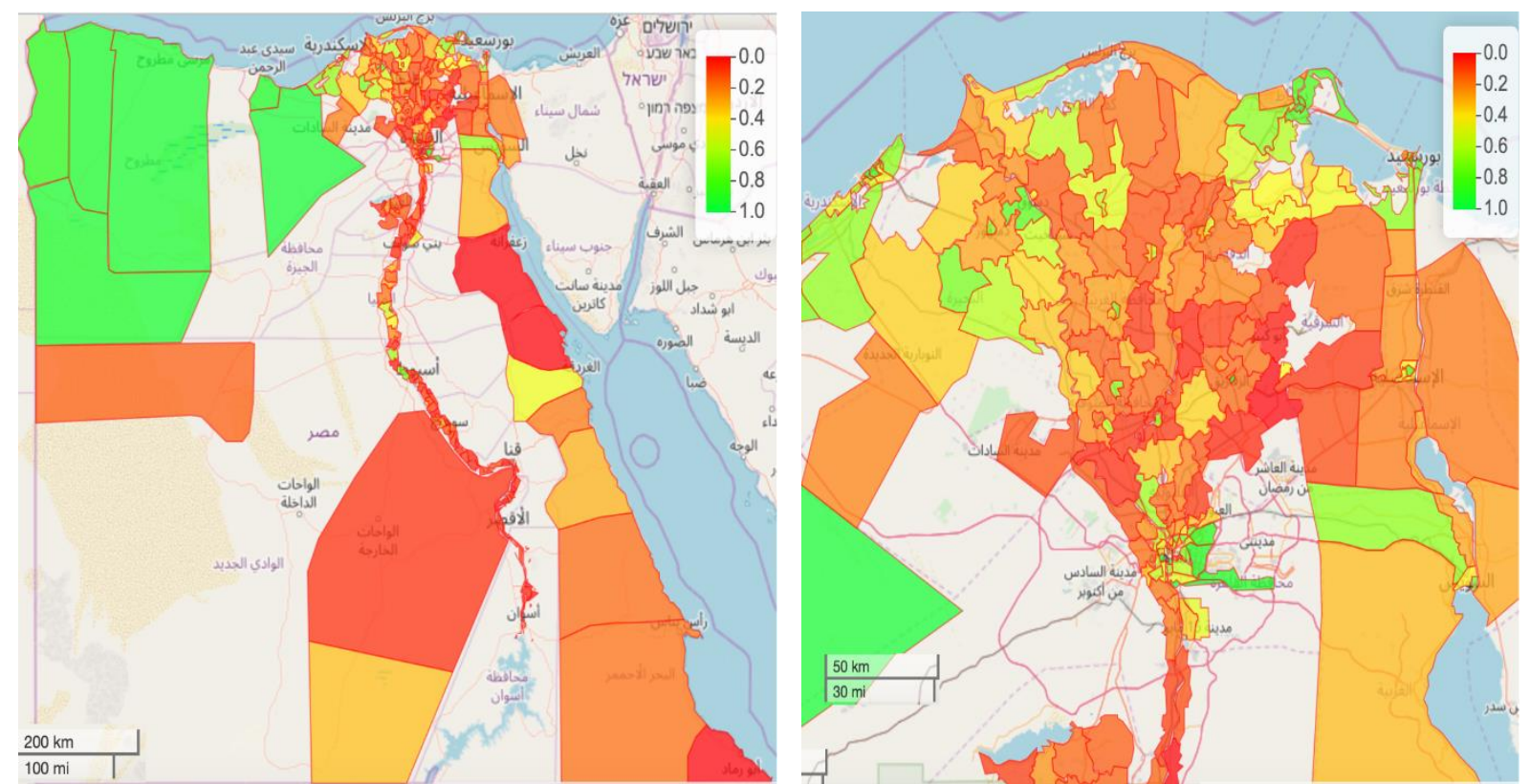

Table 3 summarises the results of the estimated two-level model. The results can be divided into two parts, the first of which presents the posterior odds ratio (OR) median and corresponding $95 \%$ credible intervals of the predictors of FGM/C abandonment (fixed-effects part of the model). The second part displays the posterior median and corresponding $95 \%$ credible interval of the parameters defining the distribution of the spatially structured random effects in the model. 
Table 3. Posterior estimates of the multi-level spatial model fitted to predict the likelihood of women aged $15-49$ years being abandoners, within the small administrative areas (kism and markaz), EDHS 2014.

\begin{tabular}{|c|c|c|}
\hline & OR & OR $(95 \% \mathrm{Cl})$ \\
\hline Intercept & $0.05^{\dagger}$ & $(0.03-0.07)$ \\
\hline \multicolumn{3}{|l|}{ Residence } \\
\hline Urban (reference is rural) & 1.16 & $(0.97-1.39)$ \\
\hline \multicolumn{3}{|l|}{ Religion } \\
\hline Muslim (reference) & 1.00 & -- \\
\hline Not Muslim & $13.56^{*}$ & $(10.54-17.66)$ \\
\hline \multicolumn{3}{|l|}{ Education } \\
\hline No education (reference) & 1.00 & -- \\
\hline Some primary & 1.17 & $(0.92-1.48)$ \\
\hline Primary complete/ some secondary & $1.67^{*}$ & $(1.41-1.99)$ \\
\hline Secondary complete/ higher & $2.45^{*}$ & $(2.12-2.84)$ \\
\hline \multicolumn{3}{|l|}{ Wealth quintile } \\
\hline Poorest (reference) & 1.00 & -- \\
\hline Second & $1.39^{*}$ & $(1.16-1.67)$ \\
\hline Middle & $1.51^{*}$ & $(1.26-1.81)$ \\
\hline Fourth & $2.10^{*}$ & $(1.70-2.59)$ \\
\hline Richest & $3.79^{*}$ & $(2.95-4.84)$ \\
\hline \multicolumn{3}{|l|}{ Work status } \\
\hline Working for cash (reference is not working) & $1.17^{*}$ & $(1.03-1.33)$ \\
\hline \multicolumn{3}{|l|}{ Mother is circumcised } \\
\hline No (reference is yes) & $8.63^{*}$ & $(7.13-10.49)$ \\
\hline \multicolumn{3}{|l|}{ Age } \\
\hline $\mathrm{Ns}^{\mathrm{a}}($ age, 3$) 1$ & $1.76^{*}$ & $(1.40-2.23)$ \\
\hline ns(age,3)2 & $3.25^{*}$ & $(1.36-7.84)$ \\
\hline ns(age,3)3 & $2.59^{*}$ & $(2.07-3.27)$ \\
\hline $\operatorname{tau}^{2 b}$ & 0.50 & $(0.35-0.69)$ \\
\hline $\mathrm{Rho}^{\mathrm{c}}$ & 0.93 & $(0.85-0.97)$ \\
\hline
\end{tabular}

" $P<0.05$

a Ns stands for natural cubic spline i.e. flexible term that is used to fit the non-linear relationship with age.

${ }^{b} \mathrm{Tau}^{2}$ is a measure of the variability in the spatial random effects, i.e., the variance across the space.

${ }^{\mathrm{c}} \mathrm{Rho}$ is a measure of correlation over space. 
Results indicate that area of residence (urban versus rural) was not significantly associated with the likelihood of being an abandoner. The model highlights the significant effect of religion; the odds of being an abandoner were 15 times higher among Christians than Muslims in the same area holding all other confounders constant. There was also a significant positive relationship between abandonment and the mother's education and wealth. However, the husband's education was not significantly associated with the likelihood of being an abandoner; this could be attributed to the strong correlation between the mother's and the father's education. The odds of being an abandoner were nearly 2.5 times higher among women who had completed their secondary or higher education relative to uneducated women. The odds of being an abandoner among women in the middle wealth quintile were 1.5 times higher than those in the poorest quintile of household socio-economic status, while the odds among those in the richest quintile were almost four times higher than those in the poorest wealth quintile. Although the odds of being an abandoner were higher among working mothers compared to those who were unemployed, the strength of the association was weak. Uncut women were more than eight times more likely to be abandoners than cut women.

Estimated non-linear effects of the woman's age on the likelihood of being an abandoner are shown in Figure 7. The figure plots the estimated posterior logins of the effects of the woman's age within the $90 \%$ and $95 \%$ credible intervals. The woman's age appears to be almost linearly positively related to the prevalence of $\mathrm{FGM} / \mathrm{C}$ abandoners. The likelihood of a woman being an abandoner increased significantly with age.

Figure 7. The estimated non-linear effect of age on the likelihood of being an abandoner.

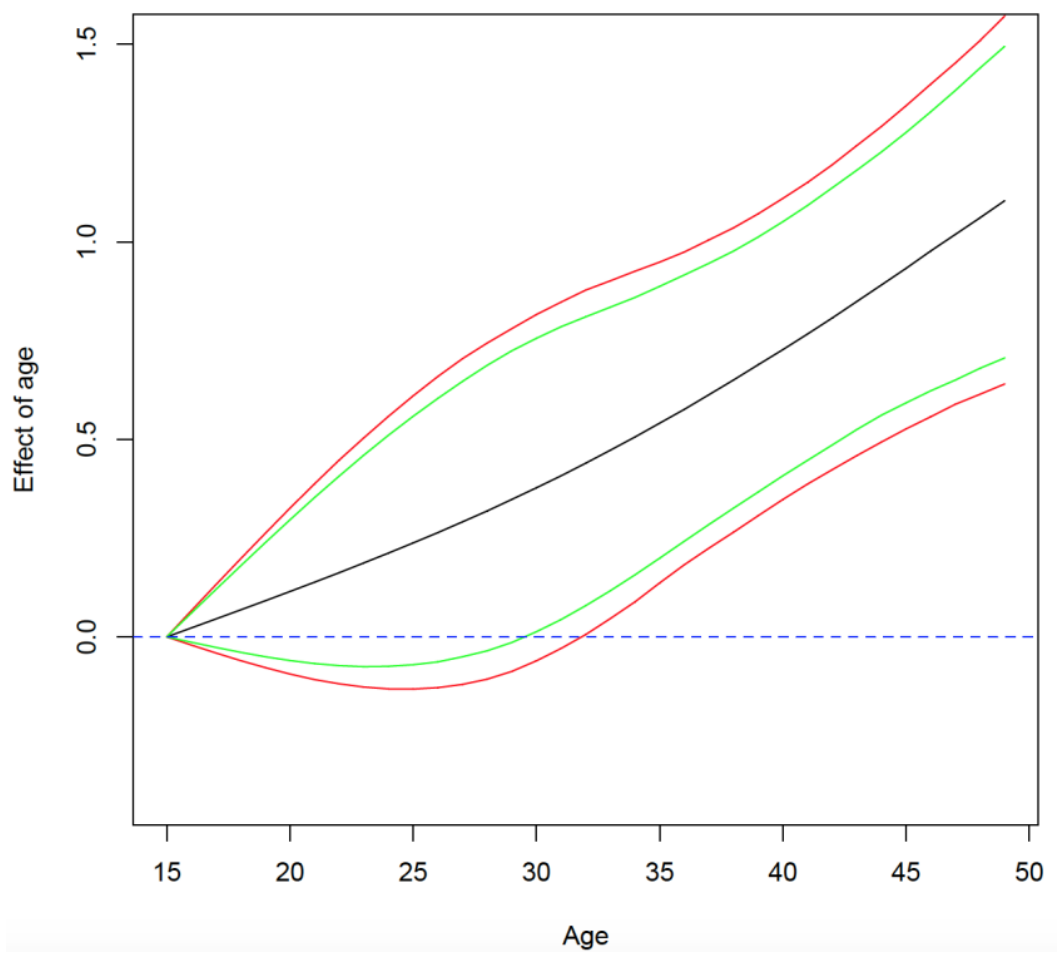

The second part of the model results indicates a strong global spatial smoothing $(\rho=0.93, \mathrm{Cl}=$ $0.85-0.97)$ and that the prevalence of abandoners varied at the kism/markaz level. This result implies that even after accounting for the socio-economic and demographic factors within areas, the geographical location (proximity to other areas) appears to significantly contribute to the women's likelihood of being abandoners. This, however, varies from one area to another. Meaning that for some areas, there is a positive spatial co-relation, that is, there is a higher tendency for 
abandonment in some areas, because they are of close distance to other areas to have abandoners, holding all other factors constant. For other areas, there was either no spatial effect or a negative spatial effect. For areas where there is a negative or no spatial effect, sociodemographic characteristics play a bigger role in whether or not one person might decide to abandon, regardless of whether they are surrounded by abandoners. For areas where there is a positive spatial effect, the existence of abandoners nearby greatly affects the odds of whether one person will decide to abandon.

The predictions of the spatial effects (the spatially structured random effects $\phi_{k}$ ) of $\mathrm{FGM} / \mathrm{C}$ abandonment are mapped in Figure 8. The figure displays the posterior odds ratios (ORs) of the residual spatial effects for FGM/C abandoners in each kism/markaz. The posterior OR range between 0.17 and 11.4, where an OR below 1 indicates a lower likelihood of finding abandoners in this area. Spatial smoothing and controlling for confounders uncover the actual prevalence of abandoners, which was difficult to see in the raw prevalence rates displayed in Figure 6 . The general patterns seen in the maps of raw prevalence rates remained unchanged. Figure 8 shows the concentration of areas with high rates of abandonment in the north-west of Egypt followed by the north-west of the delta. The map of raw prevalence rates in Figure 6 highlights low prevalence of abandoners in some areas near Alexandria. However, by controlling the effect of confounders and adjusting for the geographic location, the spatial effects become more pronounced in those areas highlighting the relatively high probability of women in these areas being abandoners. In addition, although Figure 6 indicates a very low percentage of abandoners in the northern part of the Red Sea Governorate, the bottom panel of Figure 8 shows that the effect of being in this region on the odds of being abandoner is not significant. In conclusion, Figure 8 shows a high prevalence of abandoners in the coastal regions but very low abandonment rates in Upper Egypt, especially from Suhag up to Aswan, and the southern part of the Red Sea Governorate. This finding is also supported by the map of the smoothed prevalence rates (predicted probabilities) of $\mathrm{FGM} / \mathrm{C}$ abandonment in Egypt obtained from fitting the hierarchical spatial model with spatially structured random effect at the mean values of the other predictors in the model, see Figure 9.

Figure 8. Map of the posterior odds ratio for the likelihood of a woman aged $15-49$ years having abandoned FGM/C (top) and the posterior significance of the spatial effects (bottom) in the subdivisions (kism/markaz) of Egypt governorates

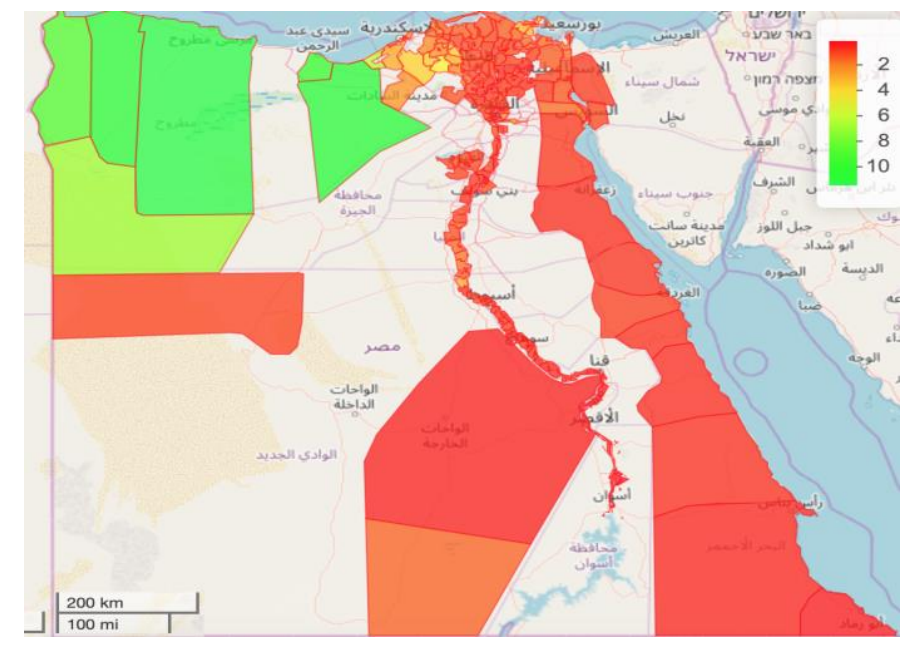




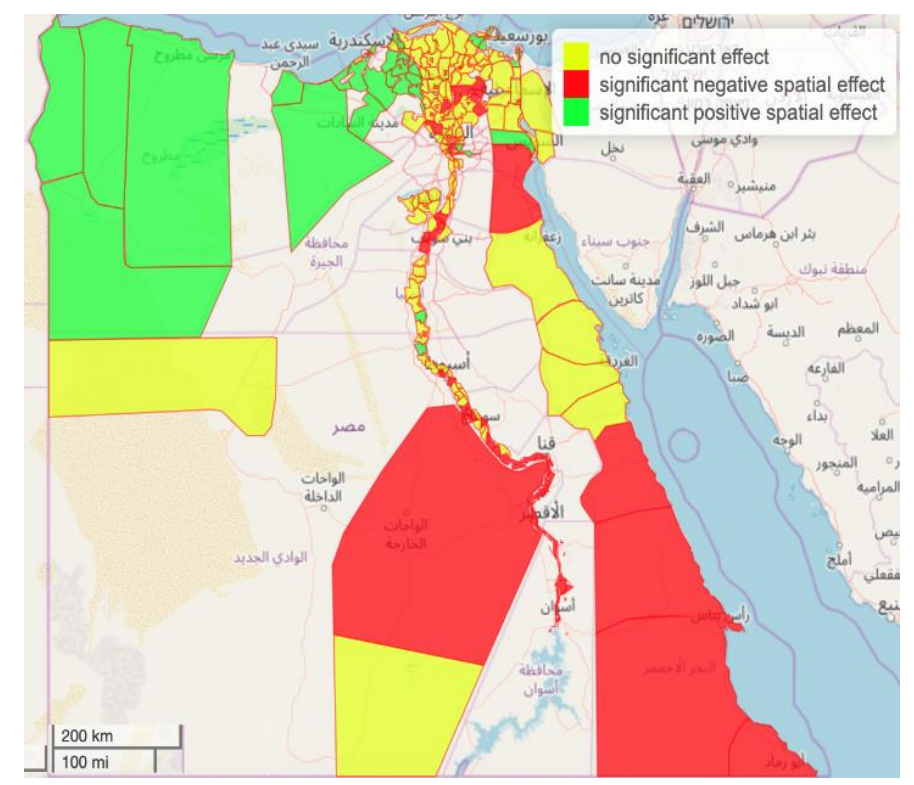

The misclassification error or the percentage mismatch between the actual values and the predicted values from the above model is $20 \%$ reflecting that the model does well in predicting the characteristics of abandoners. For assessing the goodness of fit and complexity of the model, we use the Deviance Information Criteria (DIC) developed by Spiegelhalter et al. (2002), with the model taking the smallest DIC value being preferred. The DIC of the model accounting for the spatial effect is 11781 compared to 12807 for the regular logistic model assuming independence, resulting in a better fit. It is thus concluded that the two-level hierarchical spatial generalised mixed model and the maps generated based on the results of this model consist a useful tool for monitoring, policy design, and targeted intervention to increase the people's awareness to eradicate this harmful practice in Egypt.

Figure 9. Map of the predicted mean prevalence of FGM/C abandoners (top) and standard deviation around the mean (bottom) in the subdivisions (kism/markaz) of Egypt governorates

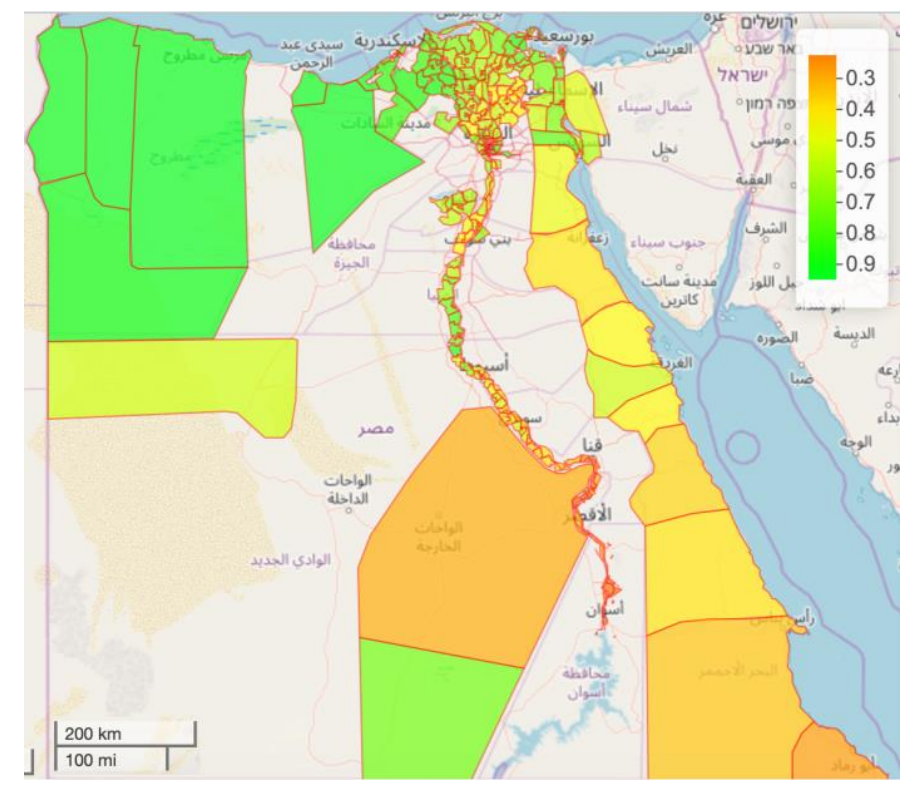




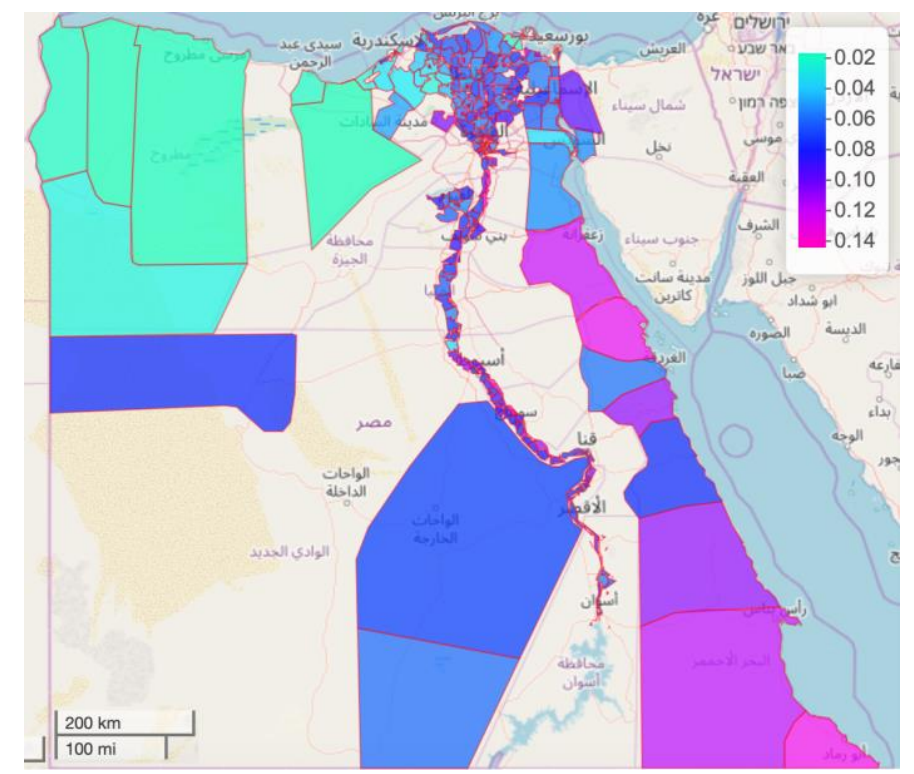

\section{Factors influencing abandonment and its sustainability}

Factors influencing the abandonment of the practice can either be internal, in that abandoners themselves are convinced that they should not circumcised, or external, in that abandoners are influenced by authoritative figures and societal pressure. We found that mothers who were convinced that they should not circumcise their daughters, usually did so out of belief that they are preserving and protecting their daughters from medical and psychological consequences, and from its adverse effects on their sexual health, which is sometimes a concern in and of itself, and other times it is a concern because of how it will affect their future husbands' satisfaction, and therefore their marital happiness. Awareness of these consequences either stemmed from mothers' personal experiences, other community members' experiences, or from media sources such as television advertisements and the internet. Some mothers, however, linked medical and psychological consequences to specific types of $\mathrm{FGM} / \mathrm{C}$, mainly those that are not "doctor authorised". While some feared that medical practitioners can also make mistakes that can lead to physical and psychological consequences, many believed that they are a safer option. Moreover, many abandoners also believed that there could still be a "need" for FGM/C, for example, in the case where the daughter is not well behaved. In which case, medical practitioners are trusted to cut off a small part of the girls' genitals (so she could maintain some sexual libido and excitement). Others believed there could be a need for FGM/C if the girl tired of her husband in bed, or if she needs to be cut for cosmetic reasons. In some cases, mothers who only had a doctor cut off a small part of their daughter's genitals, or only cut their daughters because they "needed" it did not identify this as circumcision, and considered themselves abandoners.

Externally, we found that abandoners follow religious and medical condemnation of the practice. However, these domains were not necessarily mutually exclusive as condemnation by medical professionals was sometimes built on religious reasons. For some, religious or medical condemnation was enough to skew them away from the practice. For others, abandonment aligned with beliefs, for example, that a girl should remain whole and intact. Legal condemnation did not appear to have a strong effect in single-handedly driving abandonment. While the law was noted to occasionally influence people to abandon, it was primarily noted to result in the secret practise of $\mathrm{FGM} / \mathrm{C}$ to avoid legal sanctions. 
The presence of abandoners within a community was noted to serve as a support for prospective abandoners, as did public condemnation of the practice. While some still believe marriage prospects are tied to the practice, abandoners often associated themselves with a more educated and modern sector of the community that will not marry off their daughters to less educated or traditional families. Public and private conversations were also noted to impact abandonment prospects or to lead to relapse - as messaging was reported to be conflicting, and at times, only tackled the physical consequences of the practice.

\section{Awareness of the medical, psychological, and sexual health consequences of FGM/C}

Most young women and their mothers demonstrated awareness of the negative consequences of $\mathrm{FGM} / \mathrm{C}$, including the medical risks and complications, the adverse psychological impacts, and the negative impacts on sexual health. Their narratives suggest that abandonment is, in large part, driven by awareness of these associated effects. As illustrated in the following quotes, this awareness is either drawn from the mothers' own personal experiences or via direct familiarity with someone who had suffered from dire medical consequences, a notion that is further explored in the 'other's experiences' section. TV advertisements and awareness campaigns were also sources of information on the health impacts.

\section{Medical risks and complications}

Almost all participants pointed to the medical risks and complications associated with $\mathrm{FGM} / \mathrm{C}-$ specifically excessive bleeding and death-as a deterrent factor that instils fear, which in turn fuels abandonment of the practice.

“The harms are that the girl may bleed excessively or die... we've seen cases like these... I saw that there was a girl who also died in Sharqeya. She died because of this. She bled excessively and died"

Mother, IDI, Cairo

"We were four sisters, each two close in age, so they would be cut together. My oldest sister was cut before us by a year or two, during the days of my grandmother. They cut a vein. So, it impacted us. She had to sit in a wide (traditional) bath and of course there was water which turned into a dark red. We had to call the ambulance for her that day and we took her to a hospital, and she was given stitches. This all happened when we were young girls... each time we'd wash her up in the bath more blood would come out... we were looking at each other in fear, crying, because as young kids we didn't know anything. 'What is this, mother, what is this?' we would ask, and she would say that nothing's wrong. But she was terrified... it's her daughter!"

$$
\text { Mother, IDI, Rural Gharbeya }
$$

While bleeding and death appeared to be the predominant focus in the narrative surrounding the potential medical risks associated with FGM/C, some women also mentioned the potential adverse effects of $F G M / C$ on fertility and pregnancy:

"There are lots of harmful effects, both physical and psychological. Of course, mentally it is very difficult for the girl to undergo something like this, and there are many physical effects just as I have heard... and it can also cause marital complications after the girl is married. At the same time, it can cause infertility and may affect her later when she's pregnant and giving birth..."

Mother, IDI, Urban Gharbeya

"Upon friction (in the marital relationship) the wound may open up and a lot of things may happen; she may become unwell, especially during pregnancy. All of that area will be affected and when she becomes pregnant, she will suffer"

Uncut girl, IDI, Cairo 
Participant narratives reveal that, despite awareness of the potential for medical complications, they often did not see these consequences as universally inherent to the practice of FGM/C in all shapes and forms. This means that, in many cases, negative medical consequences were only attributed to specific circumstances. For example, as $\mathrm{FGM} / \mathrm{C}$ has increasingly moved into the medical sphere, some participants solely associated medical complications with FGM/C performed by dayas (traditional circumcisers) and not that performed by doctors, displaying a bias towards what they considered 'safer' alternatives to the traditional practice. This view is illustrated in the following quotations from two urban Sohag participants:

"Yes, they say it could be harmful. Something could happen to the girl being cut. She could die... Usually it's from negligence, because in the past I heard that there used to be a daya who used to come cut the girls... but then it could be unhygienic"

Uncut girl, IDI, Urban Sohag

"It's possible that if the girl is cut by a daya, she might overdo it... and [the girl] could die... she overdoes it by cutting an unnecessary part, or, as they say, she completely eliminates the part... and this can cause excessive bleeding and lead to death"

Mother, IDI, Urban Sohag

However, a few participants acknowledged the potential for a medical practitioner-or their medical team-to commit an 'error', highlighting their recognition that medical complications are not exclusive to 'traditional' circumcision carried out by a daya. This type of awareness and dialogue can be crucial for complete abandonment, and not medicalisation of FGM/C. Meaning that recognising that the practice is dangerous even when performed by a medical practitioner, can push those who are attempting to avoid the dangers of the practice to abandon altogether, rather than to resort to a medical practitioner in faith that they are not likely to commit an error during the procedure. Recognition of the potential for medical error is illustrated in the following quotes:

"I've seen things in front of me, as girls have suffered and had excessive bleeding. For some, the doctors gave them the wrong anaesthesia. Sometimes the doctor brings with them an anaesthesiologist who isn't specialised, who gives injections that cause an intravenous blockage. This is harmful and creates an additional problem"

$$
\text { Uncut girl, IDI, Urban Sohag }
$$

"Of course, it is harmful... For example, while a doctor is doing [FGM/C] they can do it wrong, causing excessive bleeding... Or the doctor may intensely wound the girl. So, this is why I say it's wrong. It's happened in front of me, with some relatives and our neighbours. It passed, thank God, and she's fine, but others have gone into operations because of [FGM/C]. For example, the doctor could have cut her harshly and so must have an operation to fix the error"

$$
\text { Uncut girl, IDI, Rural Gharbeya }
$$

In investigating factors leading to abandonment, it is important to consider the sources of information that lead abandoners to formulate their opinions. Fear of the medical complications of FGM/C often appeared to be based on second-hand knowledge of the experiences of others who have suffered. Among mothers, familiarity with others' experiences often fuelled a subsequent desire to protect their daughters. Mothers cited the negative experiences of other family members and people in the community as having instilled the fear that encouraged them to abandon the practice:

"There was one major case which happened in front of me. She was cut and it scared me because she bled excessively and suffered, and they operated on her and sewed her up... she was honestly so distressed"

Mother, IDI, Rural Gharbeya 
"I saw and I know a lot of people and girls who bled excessively and girls who have suffered and girls who were exposed to a very intense psychological trauma and remained [like that] for a while until they returned to their normal state"

Mother, IDI, Urban Gharbeya

A mother's decision not to expose her daughter to the medical risks associated with FGM/C was often framed by the mother as part of a duty to protect her daughter; an avoidance of the "betrayal" that other people's daughters - or, in some cases, the mother herself-have experienced by their parents. For instance, when asked what benefit she gained from not having her daughter cut, one mother in rural Sohag framed her abandonment of the practice as having bestowed mercy upon her daughter:

"She was protected [because she didn't undergo FGM/C] ... she was relieved of a lot of things which could have led to her bleeding and her death"

$$
\text { Mother, IDI, Rural Sohag }
$$

Moreover, some abandoning mothers were quite expressive in their negative perception of the dangers that $\mathrm{FGM} / \mathrm{C}$ posed to their daughters. A mother in urban Sohag, for instance, categorised it as a 'barbaric' practice which induces 'violence' against the girl, and another urban Sohag mother equated performing FGM/C to executing her daughter. This is illustrated in the quotes below:

"It's violence, violence in every sense of the word... It's violence against the girl. She's only a child, for God's sake! She's taken in a barbaric way and something is taken away from her, something which God created her with... [I have this opinion] because it happened to me... and I was completely refusing to do to my daughter what was done to me."

Mother, IDI, Urban Sohag

"I've seen multiple cases of excessive bleeding... My aunts and people around us have circumcised their daughters, and l've seen girls stay for a week in the hospital because of excessive bleeding. I wasn't aware of all of this until I was asked whether l'd have my daughter cut and I said no. After what I've seen, if l'd still wanted to circumcise her, l'd be executing her... I'm a mother who is attached to her kids, and I'm not willing to make a sacrifice. l've seen that this is wrong with my nieces... I would never put my own daughter through it"

Mother, IDI, Urban Sohag

\section{Adverse psychological effects}

Intertwined within participants' narratives surrounding the medical risks of FGM/C is the recognition of the psychological effects of the practice. Psychological effects were discussed in terms of both the immediate, acute effects of the procedure and the detrimental, long-lasting trauma resulting from FGM/C. Support for abandonment appeared to stem from both a desire to preserve the girls' mental health, as well as a fear that a woman will not be able to fulfil marital duties once married due to being traumatised, an idea that will be further explored in the next section.

Some of the young women, despite having not undergone FGM/C themselves, still demonstrated a strong conviction that FGM/C causes negative short- and long-term psychological effects. Several young women noted that FGM/C ruins girls' psychological health and results in psychological crises or trauma. Lacking first-hand experience, it appears that these young women's beliefs about the magnitude of the negative psychological effects was based on other girls' experiences of FGM/C and on its depiction in television programmes and campaigns and on social media:

"Of course, her mental health deteriorates, and she doesn't want it (FGM/C) but her parents force her... She might also worsen when she looks at herself in the mirror and sees that there's a part of her body that's cut and then get angry and wonder 'why?'”

Uncut girl, IDI, Rural Sohag 
"She could go into a psychological trauma; she could be traumatised from what happened to her. That is, if it was done to her by a normal person (daya) and not a doctor. There are people who do it without anaesthesia and such...She could go into an intense psychological trauma... sometimes this could be during the actual occurrence of FGM/C and sometimes it scars her for life"

$$
\text { Uncut girl, IDI, Cairo }
$$

When asked about the benefits of abandoning FGM/C, one participant, a girl from Cairo, rejected the notion that better psychological health of uncut girls was a 'benefit' of abandonment and insisted that good mental health should be the norm. She noted, 'The girls' mental health is better, I think [if she doesn't undergo FGM/C] ... This should be the norm. Why are we saying that it's a benefit of abandonment? The norm should be that human beings' mental health is normal and good, but I think for the girl who undergoes FGM/C, her mental health is not [good]." Her views demonstrate recognition of girls' rights and fits into the 'preservation' of health and wellbeing narrative as was demonstrated by mothers' discussions of the medical risks of FGM/C.

As with the medical risks of $\mathrm{FGM} / \mathrm{C}$, mothers who had not cut their daughters felt proud of preserving their daughters' mental health, a motive that seems to win over many mothers. This concept threads into a larger narrative within which mothers have a duty to bring up unbroken, intact, and wholesome girls:

"I feel like this way, my daughter was not psychologically tormented in any way, meaning her mental health is good. I didn't pressure her or impose violence on her. Because $[F G M / C]$ is violence"

$$
\text { Mother, IDI, Urban Sohag }
$$

Several mothers, having experienced FGM/C themselves, still carried the psychological burden of the procedure and simply did not want to expose their daughters to the same 'trauma' they personally went through, showing the importance of personal experience in the abandonment decision. This is demonstrated by a mother from Cairo, who described her own experience as 'like we see on television' and insisted that she had never forgotten her own experience:

"The destructive psychological state, which continues to destroy me until this day. Can you imagine that, until now, I haven't forgotten the blade that the woman was holding...? I don't know, they brought these strange people [...] like the people you see on television. I don't know what she was holding, I couldn't see but it was basically a blade and-I swear to God I've seen this scene on television-they held me down, four women, and I felt something like an intense burn. I'm never going to forget the incident... I'll never forget my screaming until my voice disappeared"

Mother, IDI, Cairo

Participants often framed the impact of the negative psychological effects of $F G M / C$ within the context of marital relationships, highlighting how concerns about the psychological impacts are actually rooted in an underlying worry about girls' ability to perform in their societally assigned future roles as married women. Accordingly, several participants saw the potential for the psychological trauma of $\mathrm{FGM} / \mathrm{C}$ to cause women to withdraw themselves from sexual relations with their future husbands, or to become a 'weak' partner within their future marital relationship:

"The psychological effects, of course they affect the girl. They make her hate her whole life and to hate men and marriage, and it has a deep effect on the girls' mental state..."

Mother, IDI, Urban Gharbeya 
"The advantage [of abandonment] is that the girls' personality becomes strong. A girl [who undergoes FGM/C] becomes weaker due to the shock of the incident and what's happened to her, so it makes her personality weaken, and she's lost something... She never forgets, she always remembers the incident and it negatively affects her psychological state and in marriage later on"

Mother, IDI, Urban Sohag

\section{Marriage, sex, and 'good' behaviour}

A considerable proportion of the study participants recognised 'sexual frigidity' as a consequence of $\mathrm{FGM} / \mathrm{C}$ and of the psychological effects of $\mathrm{FGM} / \mathrm{C}$. The narrative surrounding sexual frigidity fell within two categories: what FGM/C may take away from a woman (losses) and how FGM/C can impose additional complications for a woman's life (complications). In terms of losses, mothers and several girls recognise the potential for FGM/C to take away a woman's sexual satisfaction with her husband:

"Me and my sisters, I feel like we all have the same problem. All three of us when we were cut. When we talk about this, I feel like that we were exposed to a lot of psychological pain and that's even made us not enjoy this type of relation [marital]... I don't like it."

Mother, IDI, Urban Sohag

"From what I hear from my friends, [for a circumcised girl] there's sexual dysfunction and reduced sexual desire... the cut woman doesn't have as much sexual sensation as the uncut woman"

$$
\text { Mother, IDI, Urban Sohag }
$$

While the conversation surrounding the woman's lack of sexual satisfaction frames the loss as a loss for the woman, oftentimes the narrative shifts to the woman's inability to take up her role as a wife, as seen in the section on the psychological effects. Participants often noted that sexual frigidity resulting from FGM/C can cause marital complications for a woman and her husband, leading a woman to not 'want' or accept sexual relations, as well as to fear her husband when she recalls the experience of being cut. The following quotations shed light on this opinion:

"Essentially, she becomes sexually frigid. No one circumcises anymore... the girl doesn't accept her husband sleeping with her, she rejects him"

Mother, IDI, Rural Gharbeya

"A million percent [there are disadvantages to $F G M / C$ ] ... I heard a doctor who said once that if a girl is cut, something occurs in the brain that makes the girl's reproductive organs tense up during intercourse with her husband... That's the most important thing: that she's not comfortable with her husband. (Lowers voice) ... It happened to me...When I got married, whenever my husband would get comfortable with me, l'd feel suffocated [needed space away] from him, suffocated, suffocated. And he'd tell me there are women who enjoy this, why are you suffocated from me?' And l'd say 'I don't know'”

Mother, IDI, Rural Gharbeya

Further shifting the narrative away from the personal loss of cut woman and towards her inadequate performance in her role as a wife, some participants indicated their perception that cut women are not 'good' for their husbands. This frames the woman's loss of sexual pleasure as more of a nuisance and dissatisfaction for her husband than it is a personal loss for the woman. Several participants mentioned that a cut woman's husband dissatisfaction with the relationship may lead him to wish to leave her:

"When a girl gets married and she's cut-extremely cut-about three quarters of men complain about her... It eventually affects the marital relations... and he's forced to leave her or marry an additional woman... "She's frigid," men will complain"

Mother, IDI, Cairo 
"When a woman gets married, FGM/C I think harms her... She's not good for the husband. She's frigid and she has no desire and she could be harmed. She doesn't even accept the relationship between her and her husband."

Mother, IDI, Urban Sohag

Several participants also extended the narrative of a husband's dissatisfaction with the woman's sexual frigidity to a social issue, attributing the high divorce rates in Egypt to FGM/C, with men's dissatisfaction driving them to ask for a divorce:

"Of course, the frightening divorce rate that exists is related as it certainly, certainly has a cause... Yesterday there was a study or something on Facebook that said the Egypt is almost highest around the world in divorce rates... Obviously these things matter a lot to our people"

Uncut girl, IDI, Cairo

"There are a lot [of people who got divorced or separated due to FGM/C] ... problems have happened because of this. For example, the wife might not satisfy the husband because she doesn't have [a sexual appetite], so this causes a problem and the man divorces her... he'll say, "she's not making me comfortable" and divorce her"

Mother, IDI, Cairo

The sexual consequences of FGM/C were often seen as a double-edged sword. Girls who were cut were 'too cold' whereas girls who were uncut were perceived to have too much sexual energy. For instance, one girl in rural Gharbeya commented on her friend who is cut, whose husband complains that she is too frigid, and her uncut friend, who seems to always need her husband, and extends the idea of 'hyper' sexuality, giving examples of uncut women who seek out same-sex relations through social media sites in order to satisfy their limitless sexual needs:

"For example, the one who's circumcised came and told me: "My husband is asking me why are you so frigid and why is there no reaction between me and you and ... there are people who are married and who always want their husbands to be with them and to be in their arms. Why don't I feel this with you, why don't I feel desired by you?", and when you ask her what she feels when she's with him, she says 'nothing, with him I'm just like you do whatever, you are free to do whatever you want to do." This is the one who's circumcised. But the uncircumcised one, she used to say 'I can't sit with my husband a lot, a lot of the times I have [sexual] needs and he says no, I'm busy' or he makes another excuse, even though she wants [to get intimate] ....and this makes her resort to inappropriate behaviours, like for example getting to know someone online, whether it's a man or a woman. Honestly, a lot of women get with women. Lesbianism has really spread on Facebook especially with the lack of FGM/C... it has its drawbacks"

Uncut girl, IDI, Rural Gharbeya

The discourse around sexual frigidity being a negative consequence of FGM/C is exclusively limited to the sphere of marital relations. When the discussion around sexuality and FGM/C expanded beyond the realm of marriage, it moved from a discussion on the relationship between $\mathrm{FGM} / \mathrm{C}$ and sexual satisfaction towards a discussion on the appropriateness of behaviour for unmarried girls. One unmarried girl in rural Sohag, who was not cut but seemed to show some level of support for the practice, believed that FGM/C can be useful before marriage, curbing a girl's sexual desires, but then harmful within the marital relationship:

"I think [the people who have stopped FGM/C] are crazy!... But at the same time, it has a negative effect after marriage... We want sexual desire to be reduced, but then after she gets married it's also reduced towards her husband... that's is what I'm conflicted about!"

Uncut girl, IDI, Rural Sohag

A few of the girls interviewed mentioned their belief that there are various degrees of cutting; that is, FGM/C can be done in a way to limit, but not completely eliminate, a woman's libido. The perceived advantages of $\mathrm{FGM} / \mathrm{C}$ reported by abandoners reveals an underlying obstacle for the 
sustainability of abandonment of FGM/C: the belief that high libido in a woman must be tempered. This belief is illustrated by a girl from rural Gharbeya: "At the beginning I was definitely against FGM/C but then when I saw the other side, I
started thinking about it a bit more... I started reading more and understanding more...
Now my thinking is that if a girl goes to a doctor and the doctor says it's needed then, yes,
she should go get cut. But only to the degree that doesn't make her neither too frigid neither
too aroused."

Uncut girl, IDI, Rural Gharbeya

FGM/C is generally understood by participants to curb a woman's sexuality, although participants differed in their beliefs regarding whether it could impact how the girl actually acts. Participant narratives suggest that the reason many people believe $F G M / C$ is unnecessary is that if a girl is raised 'well,' then FGM/C is uncalled for. Associations between FGM/C and girls' sexual excitement and behaviour were disregarded by some women, and instead the effect of environmental and relational factors on sexual behaviour was emphasised. Confidence in the girls' upbringing-and consequently, her good behaviour-was a significant determining factor for those who saw that FGM/C was completely unnecessary to moderate an unmarried girl's sexuality and behaviour:

"My daughter was in school back in the day and the girls would tell her 'my mother is going to circumcise me.' So, my daughter came to ask me what that meant, and I told her 'Darling, this is something that people do... but we aren't going to do it. We are well brought up and we preserve ourselves and that's all.' I told her 'this has nothing to do with whether you're well behaved, listen to your mother.' [... If I was worried about her, I wouldn't allow her to leave the house or enter university. I'd have her sit next to me. No, I need to raise my daughter well and release her into to world to deal with it."

Mother, IDI, Urban Gharbeya

"Yes, I address FGM/C...the whole family and the other people coming from [rural areas] or the people in the streets around us... Yes, l'm proud I didn't cut my daughter and it's good that she walks around like this: a well-behaved, uncircumcised girl... And this is proof that behaviour is reliant not on FGM/C, but on upbringing"

$$
\text { Mother, IDI, Cairo }
$$

What exactly is meant by a girl who behaves 'properly' appeared to be only vaguely understood. Some participants linked "good" behaviour to the girl being obedient and "calm". Others mentioned that their daughters are well behaved since they do not seek to speak with males. However, the emphasis by participants on the girls' 'good' behaviour highlights a differentiating factor which, among some abandoners, may represent the tipping point between abandonment and continuation of the practice. Several of the women and girls interviewed explicitly expressed that if a girl were to behave inappropriately, then FGM/C should be considered, highlighting the fragility of abandonment status. The following quotes shed further light on this issue:

"I used to see when I was younger in high school, and I didn't know what was happening, like FGM/C or not... I didn't know what was going on. But then you start to understand. There are things you just start to feel. There are feelings towards sex. Since then, l've started searching about it more, but my opinion mostly hasn't changed. I used to say: 'why would we circumcise if the girl is well behaved?' Also, when I saw that the majority of girls who were cut experienced sexual frigidity with their husbands... I started saying 'but why damage the girl and what's the purpose of FGM/C?'... But then when I started seeing that there are girls searching for inappropriate things because they aren't circumcised, I started to become conflicted between the two... But I started to look a bit more and found that some people need to be circumcised and for others there's no need at all"

Uncut girl, IDI, Rural Gharbeya

"No, I honestly didn't take them to a doctor... because they're good and tame...if I saw her eyeing [men], talking to guys or something, l'd know she has leniencies towards 
[inappropriate behaviour] so l'd take her to be checked by a doctor... The medical experts can then do what they see fit"

Mother, IDI, Cairo

\section{Sources of information}

Participant narratives also indicated that fear of the medical complications associated with $\mathrm{FGM} / \mathrm{C}$ is not just based on real-life anecdotes, but is also based on its depiction in television series and through information obtained on the internet, as illustrated in the following quotations:

"Look, because I grew up in an environment which has ignorance entrenched from the past, no matter how much I grew up, went out and worked about, got married, and saw things, I started to think about the matter [FGM/C]. There was a huge campaign on television during the days of [the previous first lady], "No to Circumcision", and they got cases that were bleeding... so when I saw this it reminded me of what happened to me when I was young. My own daughter was young at this point and I started thinking about whether l'd circumcise her when she gets older or not. But then when the television programmes came on and there were girls that died because of the bleeding and stuff, I said no, I won't circumcise her, no matter what happens. After I saw these images, I said no, I'm not willing to sacrifice my daughter"

Mother, IDI, Cairo

"I also heard that there are people who can bleed and people who die because of this, and we've heard a lot and watched a lot of television series and movies that depict FGM/C and show a girl who was cut and suddenly dies... l've mostly heard about this on television... mostly movies and series that we used to watch that would warn people against FGM/C and said that people die from it"

Uncut girl, IDI, Rural Gharbeya

"There are videos on the internet about the psychological pains and the amount of physical pain and hurt that FGM/C causes"

Uncut girl, IDI, Urban Sohag

\section{Personal experiences fuelling abandonment}

Findings reveal that the experiences of the mother in the abandoning family, as well as the experiences of others in the family and community, were highly significant in shaping the opinions and affecting the choices of abandoners. Experiences and notions of fear, trauma and suffering were crucially woven into the narratives of abandoners, as discussed in this section. This, however, could go both ways. According to the spatial analysis, mothers who were cut were eight times more likely to cut their daughters-holding other factors constant (geographical location). While the qualitative data shows that women who have a traumatic physical or psychological experience, or who have had unhealthy marital relationships due to their circumcision status, might refrain from cutting their daughters, it is important to remember that this is not the norm. And that when looking at the wider picture, cut women are still much more likely to cut their daughters.

\section{Mother's personal experience}

Participant's narratives suggest that mothers who had bad personal experiences with FGM/C were likely to indicate that their own experiences were a strong influencing factor on the abandonment decision. Sometimes, this was framed in terms of the harsh memory of their actual experience:

"In the past it used to be that the girl had to be cut... Why? They would say it's for the girls' chastity... I didn't know what that meant. I was young, very young. I hadn't turned 8 years old and suddenly they grabbed me, and it was same as you see on television right now. It's butchery, it's not circumcision. It's butchery. Up until this day it's shaken me. Also, with the marital relation, I can't even begin to tell you [how it is]." 
"I remember I was held down in a very strange way. Two plump women grabbed me, and one of them kept cutting me with a blade. The pain was terrible; I can't describe it to you. To the extent that I almost fainted because of the pain"

Mother, IDI, Urban Sohag

One Cairo mother, who claimed that she had been married and divorced three times because of her lack of sexual desire, admitted how despite pressure from her mother, the pain she endured did not allow her to expose her daughters to the same experience:

"Many times my mother tells me [to circumcise my daughter] and I comfort her and say 'okay,' okay, mom, I'll do it (cut my daughter) and l'd just be quiet...In my mind I couldn't imagine doing that to them. Because I was hurt. I was hurt. I was hurt. I was hurt and in so much pain... I felt like there was a wound and there were things that hurt, and I stayed hurt for a while, unable to return to normal and to walk freely"

Mother, IDI, Cairo

Recollection of the harsh memories of undergoing FGM/C often led to a discussion of the consequent effects on the woman's marital life. For several women, the hardships they faced within their marital relationship and the dissatisfaction they felt with regards to their sexual life significantly shaped their opinion. These mothers felt a duty to preserve their daughters' ability to enjoy a healthy married life, and to prevent them from undergoing the suffering that they themselves went through:

"I didn't know that it could be problematic in my marriage. I didn't know it's harms. All I know is that I was so in pain and I remember what the situation I was in looked like and that the pain stayed within me, in my soul. Yes, I recovered from the wound down there, but inside my soul I didn't. When I got married and I couldn't feel any pleasure, I wondered... 'Is this marriage? How is marriage good then?' [...] It's a good thing I didn't circumcise [my daughter] so that she doesn't suffer the same suffering I did when she gets married."

Mother, IDI, Cairo

"Look, I don't know. They say that there's a marital life... a lot of people say that they are able to have pleasure with their husbands and stuff, but I haven't experienced this. I don't know anything about this. What happens to me is like a tensing up, and things hurt me, and I can't endure anyone coming near me. Even when I rinse (my genital area) this area hurts. They obliterated me... you can't imagine! They slaughtered me, they slaughtered me, they slaughtered me!"

Mother, IDI, Rural Gharbeya

\section{Others' experiences}

While the magnitude of the effect of mother's personal experiences may provide a strong push for abandonment, awareness of other peoples' negative experiences may also be a powerful deterrent from FGM/C. This could explain the strong positive spatial correlation found in some parts of Egypt, which suggests that there is a higher tendency to share others' experiences openly.

Participants displayed awareness of the negative consequences of FGM/C—the medical risks, the psychological effects, as well as the reduction of a woman's marital satisfaction-based on the experiences of surrounding family and community members, and this impacted their decision to abandon. For example, several participants cited the experience of family members with excessive bleeding as having had a significant influence on their opinions on FGM/C, as illustrated by this rural Sohag mother:

"I rejected FGM/C before the campaigns because I saw several cases that were psychologically traumatised and had excessive bleeding. And my niece was cut and had excessive bleeding and would have died, despite them having saved her with an injection" Mother, IDI, Rural Sohag 
As illustrated in the above instances, several participants also noted that their anti-FGM/C stance was based on the resultant psychological trauma experienced by a community member, for example, a neighbour or another connection, and displayed awareness of the post-marital negative consequences:

"[My personal opinion is based on] the television and on what happens around us. In the past we were in an old house. There was a neighbour, a girl, who had this happen to her, and her psychological health after marriage was ruined. Because it affects the girls' mental health and stuff, so I wouldn't want this to happen with me, or with any other girl."

Uncut girl, IDI, Urban Gharbeya

"I found out [about the harms] from a friend who had married her daughter off and she was saying that not circumcising is better... because some problems occurred between the girl and her husband"

Mother, IDI, Urban Sohag

\section{Authoritative condemnation of the practice}

Beyond awareness of the potential negative consequences of the practice, abandoners often displayed a conviction that they were succumbing to various forms of authority that had condemned FGM/C, namely religious reproach, the anti-FGM/C law, and medical disapproval of the practice. Religious condemnation of the practice often echoed beliefs that a girl should be kept whole-since this is how she was created by God and should be protected from harm. Interestingly, religious authority and advice was also sometimes passed by through medical professionals as authoritative figures in the community.

While for some, religion, medicine and the law served as just another source of information, for others, the condemnation of the practice, especially by religion and by the medical community, was enough to deter them from circumcision.

\section{Religious condemnation}

Religion has historically been cited as a key factor supporting the continuation of FGM/C; it has traditionally been considered a religious obligation by those who practice it (Malmström, 2016). Narratives from study participants, however, suggest that a significant factor in the push for abandonment is the progressive view that FGM/C is condemned by Islamic and Christian religions, or 'haram' (sinful). It is also important to note that Christians were 15 times more likely to abandon FGM/C compared to Muslims, controlling for other factors such as education, wealth quantile, work status, the mothers' circumcision status, as well as residing in an urban or rural area. This finding underscores the centrality of religion in the decision to abandon. Findings from the IDIs suggest that, across the board, many of the young women and mothers interviewed believe that $\mathrm{FGM} / \mathrm{C}$ is a sinful practice ('haram') and that therefore they, and others, should not practise it. This view is illustrated in the following quotes:

"In our community [FGM/C] is forbidden and in the Bible it's also rejected. Of course, religion rejects it, so the community rejects it because it is something that's harmful"

$$
\text { Mother, IDI, Rural Sohag }
$$

"What convinced me is that there are a lot of people who are cut and who still act wrongly. It all comes back to upbringing, I'm convinced of this. And Sheikh Shaarawy, God bless his soul, is the one who convinced me. I used to listen to Sheikh Shaarawy and others on the television channel, and they used to say it's wrong and haram"

Mother, IDI, Cairo

"This is something which God created us with, so it's haram to cut her [...]. Religion didn't call for [FGM/C]"

Mother, IDI, Rural Sohag 
Many participants cited this negative religious connotation as the sole motivation for the discontinuation of the practice, without displaying critical assessment or acknowledgment of other potential reasons for abandonment. This poses a danger to abandonment efforts, as religious messaging remains inconsistent, meaning that participants who only relied on religious reasons not to circumcise, without understanding the harms of the practice, would be prone to relapse. For instance, when asked whether there are drawbacks to FGM/C, one girl in rural Gharbeya denied awareness of any downsides and simply said it is "haram". Similarly, one mother in rural Sohag was adamant that she would not do it solely because FGM/C is "haram", denying awareness of any effect of FGM/C on other aspects of a woman's life:

"No [my decision wasn't based on her future marital relations] I am convinced that, since it's been proclaimed in this way, then it's haram...The relationship between a man and a woman exists between the man and the women and is based on mutual understanding and their relationship and their satisfaction. As long as things are working well then their marital relation has nothing to do with FGM/C. I announce this with confidence."

Mother, IDI, Rural Sohag

As testament to the influence of external pressure and social/religious norms on abandonmentas well as continuation - of the practice, a phenomenon further explored below, some participants mentioned that they were 'told' that FGM/C is condemned by religion from various sources, including family members, television and local awareness campaigns. These women accepted this categorisation of the practice in order to conform to what they have been told is religiously correct, as illustrated in the following quotes:

"It's better [to abandon FGM/C] ... they say that circumcision is haram [...] I used to see an advertisement that would say that FGM/C is haram, it would always come on television." Uncut girl, IDI, Urban Sohag

"I heard my grandmother saying that [FGM/C is haram] and of course she prohibited anyone in our family from performing FGM/C and she always says it's haram and prohibited for girls."

Uncut girl, IDI, Rural Gharbeya

Conversations like these, which influence people's opinions, and thus their abandonment, of FGM/C, are further explored in the 'conversations' section below. For some women, it was medical doctors who convinced them that FGM/C is "haram", representing how religious messaging is not solely spread via religious figures, but through other 'trusted' community members, like doctors. It appears that doctors' advice is not limited solely to medical information (as described in the section below), but that their voice is also authoritative in other societal realms:

"They told us it's haram...Doctor (name of doctor), who is my cousin [...] ever since l've grown up, they say l've heard it's haram so that's final, I wouldn't do anything to anger God. [My opinion on FGM/C] is based on religion and sharia (religious law), since I know, or I find out or a doctor or someone says this is haram and backs it with a hadith. Mother, IDI, Rural Sohag

It is also important to note that religious messaging on the abandonment of FGM/C appears to also reach and affect male community members. This point is further explored in the public conversations section below. For instance, for one of the mothers in rural Gharbeya (who had had her eldest daughter undergo $\mathrm{FGM} / \mathrm{C}$ and abandoned the practice for the younger girls), it was her husband's awareness of the $\mathrm{FGM} / \mathrm{C}$ campaigns and their religious messaging which prompted her to think twice about performing $\mathrm{FGM} / \mathrm{C}$ on her daughter:

"I honestly took my daughter to be checked by a doctor and he said she's fine, she doesn't need it. So, I acted accordingly, and I didn't take my other girls to be checked. Her dad had asked me 'Where are you going,' so I told him, and he asked why I wanted to circumcise her. I told him that I'm just going to go check on her. If she needs it, I'll circumcise her, if 
not then so be it. He told me why are you doing that? They're saying 'No' on television and that it's haram, don't circumcise the girls, and that things happen to the girls. Honestly, I said l'd take extra precaution and just check the girl. But I got scared"

Mother, IDI, Rural Gharbeya

\section{Legal condemnation}

A few participants displayed familiarity with the law against $F G M / C$, to various degrees (i.e., who is prosecuted, where it is enforced). However, the law was not highlighted as the primary push factor for abandonment for any of the families included, and it was not mentioned by participants as often as religious and medical push factors. A few mothers expressed awareness that doctors carrying out FGM/C may have their practice closed because of the law banning it, and as a result doctors were no longer practising FGM/C. One participant, a mother in rural Gharbeya who had decided to have her two older daughters circumcised, was discouraged from FGM/C for her two youngest daughters by her Cairo-residing mother-in-law, who warned her that the law holds parents, and not just doctors, accountable for FGM/C:

"I heard from [my mother-in-law] ... they're in the greater Cairo governorate so we usually stay there for two days, and here for two days. So, my mother-in-law told me not to [circumcise my girls] and that it causes infertility and the girl becomes jinxed and delayed in her pregnancy. And she also told me that the legislation has come out that whoever they catch circumcising her daughter will be reported...as well as the doctor and anyone else who performs it. I was convinced by her. I mean, she's the older one"

Mother, IDI, Rural Gharbeya

As with the aforementioned example of the husband's awareness of the religious condemnation of $\mathrm{FGM} / \mathrm{C}$, the above case further displays the power of widespread awareness of authoritative condemnation of the practice to filter through family members and influence the final decisionmakers. One Cairo mother mentioned, however, that awareness of the law did not seem to be a sufficient push factor to encourage people to abandon the practice. For example, she noted that those who perform FGM/C in Cairo are somewhat aware of the legal crackdown but are pushed towards operations in rural areas instead of total abandonment of the practice. The participant discussed how the law is creating awareness among some cases, but is pushing the practice underground in others:

"There's a law now, and there's a fine, so people are scared and there's a village that people go to in the rural areas. They circumcise in secret. But before the law, they used to circumcise their daughters at the doctors"

$$
\text { Mother, IDI, Cairo }
$$

\section{Medical opinion}

Findings reveal that health care providers are widely regarded as safe and knowledgeable sources of information regarding FGM/C. Almost half of the uncut girls interviewed had been taken to a doctor to be 'checked' to see if they 'needed' it. In Cairo, this was universal among participants, as well as in rural Gharbeya. Doctor visits appeared less common among participants from urban Gharbeya and were not apparent among participants from Sohag.

The prevalent 'progressive' discourse on FGM/C and its potential harms appears to have resulted in some parents questioning the practice, and thus seeking advice from health care providers. Participant narratives underscored that for some mothers, consulting physicians about the need for $\mathrm{FGM} / \mathrm{C}$ allowed them to distance themselves from what they considered 'traditional', unnecessary circumcision and allowed them to position themselves in an educated, 'cultured' band of society. One mother, who was cut by a doctor as child, praised her parents for taking her to a doctor and not a traditional circumciser (daya), despite the trauma of the experience, implying that this was a more 'dignified' or civilised way of cutting: 
"They circumcised me like any other girl at the age of cutting, like 10 or 12 years old. But they took me to a doctor. I mean, my parents are not extreme to the extent of doing it at home and stuff. No, no, my parents took me to a doctor. But I still remember the day. They tricked me and they told me I was just going to a doctor to get a check-up and then I found out what was going to happen to me. After that, I can't explain what happened, but I just didn't want to expose my girl to the same situation."

Mother, IDI, Urban Gharbeya

Even among doctor-authorised abandoners (i.e., those who were told by a doctor that their daughters don't 'need' circumcision), discourse on the performance of FGM/C by a doctor was often distanced from 'traditional' FGM/C through its characterisation as 'cosmetic surgery'. Some mothers, discouraged from performing $\mathrm{FGM} / \mathrm{C}$ on their daughters by a doctor, were keen to separate themselves from those who intend to practise FGM/C, justifying their medical enquiry as progressive in case the girl needs cosmetic surgery to 'beautify' the genital area, rather than as an intention to potentially perform FGM/C:

"IIf you take her to a doctor] then it's not called circumcision. Then that's cosmetic surgery... like if there are parts outside the labia and inside is coming out, this is what you would remove. This is what I saw on the internet. There are cosmetic surgery procedures. I saw the infographics which explained what's what... between the two labia there's a part that's coming out; this is only what's removed. But when I was cut, they took it all"

Mother, IDI, Cairo

Some women, hesitant to take the final step to fully abandon the practice, entrusted doctors who had the expertise and ability to assess the condition of a girl's genitals and determine girls who 'need' it and girls who do not. There was a common belief among abandoners that some girls may require $\mathrm{FGM} / \mathrm{C}$, and that mothers are doing the right thing by taking their girls to be checked. Accordingly, these mothers are comforted in not being 'active' participants in the abandonment decision-making process and, instead, in having deferred this decision to the medical experts and following their verdict. This is illustrated in the quotes below:

"I wish all women would take their daughters to the doctor to see if she needs it or not, so that no complications occur between her and her husband, and so that her psyche isn't worn-out. The correct thing to do is to take her to a doctor. Doctors have more knowledge than we do. They know what's right and what's wrong. They've studied for a number of years in medical school, they're a surgeon. So, they know, they have a background"

Mother, IDI, Rural Gharbeya

"And I asked a doctor who also told me the same thing. He said you don't have to cut them. Like, I didn't just leave them like this of my own volition. I took them to be examined"

Mother, IDI, Cairo

The girls included in this study who were taken to a doctor were told that they did not 'need' it, demonstrating the potentially immense role of medical practitioners to push for abandonment of the practice. Accordingly, the FGM/C decision is taken outside of the home and is increasingly in the hands of doctors. The following quotes depict the role of doctors in influencing the final FGM/C decision:

"If the doctor told me [my daughter] needed FGM/C, l'd see her and check if she needs it, and l'd tell [the doctor] no, haram and it's not worth it. She doesn't need it and she's fine"

Mother, IDI, Cairo

"We went to a doctor and he checked me. They [my family] told me we were running an errand [rather than telling me that we were going to the doctor]. I didn't know so I was so scared and terrified when I saw the doctor, I was even more terrified. Thank God he told me there's nothing like this and I told them at home that no one should do this again. I told them it's haram, by the way, this is something wrong. You have to embarrass yourself 
exposing yourself to someone you don't even know. I was so, so, so embarrassed! For someone else to look at you like that it's something so embarrassing"

Girl, IDI, Rural Gharbeya

The decision-shifting power of doctors holds true even among some mothers who had originally decided to have their daughters cut. For instance, one mother who had decided to circumcise her daughter was prompted by her husband to check with a doctor first, after he had heard about the negative consequences of FGM/C on television. The doctor was then able to sway the mother to abandon the practice:

"We grew up like this. We found that when the girl is $11-13$, they would circumcise her. And that's it. They didn't know its long-term disadvantages... it was a system of ignorance... I went to the doctor because I wanted [to circumcise her], then her father stood up to me and said no, take her to a doctor to check her. So, I went to the doctor and she said no, she doesn't need it. [...] I wanted to circumcise her just like we all grew up but then my husband refused at the time [...] because of what we hear on television and the movies as well"

Mother, IDI, Rural Gharbeya

This situation not only represents the influence of doctors in the final FGM/C decision, but also represents the immense power of media messaging in influencing the opinions of various family members who may have direct or indirect power on the FGM/C decision, as discussed later in the 'conversations' section.

The discourse around the medical necessity of FGM/C is not only limited to medical judgment but is also largely influenced by cultural constructions of bodily beauty and femininity. In speaking about FGM/C, abandoning women sometimes mentioned that some girls 'needed' to be cut depending on the size of their genitalia, casting larger genitalia as shameful and referring to 'ugliness' with regards to the size of genitalia. They believed that some girls 'need' FGM/C due to having 'extra' parts, framing FGM/C as a way to preserve a girl's femininity and marriageability, and to ensure a girl's future marital satisfaction:

"My mother had asked the doctor I went to whether I need FGM/C or not, so the doctor told her maybe a small bit, but if l'd do it, it has to be before the age of 18 because after that it becomes hard...[the doctor] said I don't need FGM/C but that I do have extra parts" Uncut girl, IDI, Cairo

Beyond the cosmetic necessity for $\mathrm{FGM} / \mathrm{C}$, there is also a misconception that for some girls, excessive itching or pain in the genital area may justify the practice. In these cases, it was implied that a doctor's opinion is needed to determine if $F G M / C$ is required, once again leaving the abandonment decision in the doctors' hands. This idea is illustrated in the following quotes:

"If the girl is complaining from [the genital area] or if it's affecting her clothing and stuff... if she's complaining we should [take her to a doctor]"

Uncut girl, IDI, Cairo

"Right before the age I should've circumcised my daughter, I had already taken my decision and I had sat with her and discussed it... but she was suffering from something down there and telling me it's itching me and it's hurting me, but she gets shy from me so I told her 'it's not a problem I can take you to a doctor and see and if that's the case, then we'll have a cosmetic operation for you,' based on what l've seen on the internet. It's called a cosmetic surgery, not called circumcision, OK?... After the holiday I told her 'What do you think? Here's the deal...' and she said she's fine now. So, I asked her 'Wasn't there something hurting you?', she said 'No, mother, not anymore...nothing hurts me anymore.' So, I told her 'Only because if there's anything, we can catch it and have a cosmetic surgery'...and she said 'No, are you kidding me, isn't this circumcision?' So, I said 'No, I'm not talking about that of course, there's a difference."'

Mother, IDI, Cairo 
Expanding on this notion, a few participants expressed the belief that girls who 'feel' a certain sensation when wearing jeans may need to be 'checked' by a doctor; a concept that threads into the larger narrative of uncut girls being easily sexually aroused and FGM/C being necessary to tame their sexuality, discussed in the section on marriage and sexuality. This concept is illustrated in the following quote by a girl from Cairo:

"[My mother] told me are you complaining about anything? Do you feel anything? So, I said no... I had a phase when I was wearing trousers all the time. So, she asked me 'when you wear pants do you feel anything? I said no, not at all"

$$
\text { Uncut girl, IDI, Cairo }
$$

Doctors also arguably play an essential role in the potential relapse of abandoners back into the practice of FGM/C. As demonstrated in the following example from rural Gharbeya, a few of the uncut girls interviewed who had been taken to doctors were told by the doctor to return in a few years, as it was too early to determine whether they would need FGM/C. This ambiguity in the decision creates space and time for families to formulate an opinion in either direction, either supporting or abandoning $\mathrm{FGM} / \mathrm{C}$, leaving the decision to circumstance instead of putting a halt to the inquiry at its foundation. While, in the case reported in the following quote, the girl's family in rural Gharbeya did not return to the doctor, other cases may do so, depending on their circumstances and environment, highlighting the potential threat to the sustainability of abandonment:

"At first, we were going to the doctor, [my mother] was insisting that this happens... that it's a custom inherited across generations, that this is something normal that must happen. And that it's a necessity. So, she went to be like everyone else and when [the doctor] said it's not needed, she was then convinced...At first the doctor said no, we can't do it now and told us come back in one or two years. We just let it go"

Uncut girl, IDI, Rural Gharbeya

\section{Social encouragement}

Similar to authoritative condemnation of the practice of FGM/C, abandoners were often comforted by knowing that others in their social network condemned the practice. This external support came in the form of social support (both real and assumed) from their family and community, as well as public condemnation of the practice in awareness campaigns and on various media sources. The topic of FGM/C surfaces in conversations in both the private and the public sphere, and when the messaging was anti-FGM/C, the conversations appeared to have influenced the opinions and the abandonment decisions of the study participants. However, as opinions on FGM/C may differ widely, conversations on FGM/C also have the potential to threaten the relapse of abandoners back into the practice.

\section{Support network}

Many of the participants interviewed, particularly mothers, assumed that FGM/C is a thing of the past, something that older generations used to do and that is much less common nowadays. Confidence in the rarity of $\mathrm{FGM} / \mathrm{C}$ and the belief in the existence of many other abandoners appears to be a comforting assumption that fosters space and encouragement for $\mathrm{FGM} / \mathrm{C}$ abandonment and discourages relapse. This belief is illustrated in the following responses by mothers, when asked how common FGM/C is now:

"I think it's very rare now to find a circumcised girl. There's no percentage. From what I see and from the people I know now, there's not a single circumcised girl"

$$
\text { Mother, IDI, Rural Gharbeya }
$$

"It's really lessened, I don't think anyone from those whose children grew up in front of me who's gotten married and had children [is circumcised]. I think it no longer exists. I think in the urban area no one circumcises" 
One girl from urban Gharbeya stated that $\mathrm{FGM} / \mathrm{C}$ is virtually non-existent within her group of friends , and that, until she met a rural girl during university, she had never met any girls her age who had undergone $\mathrm{FGM} / \mathrm{C}$ :

"No, I don't think it's prevalent. Most of my friends are exactly like me. No one's had [FGM/C] happen to them, until I got to university and I met rural girls, then I met one who had undergone this. Otherwise, I don't think it's common [...] I personally have never met except one person, and she was from the rural, not urban, area."

Uncut girl, IDI, Urban Gharbeya

This perceptive division of 'us' and 'them' is not exclusive to urban versus rural residents. It surfaces often in the discourse regarding the prevalence of $F G M / C$, with abandoners self-categorising as "civilised," "educated" and "progressive" versus the "ignorant" people who abide by "old traditions." This is illustrated in the following quotes which further shed light on abandoner's assumption that $\mathrm{FGM} / \mathrm{C}$ is a rare practice nowadays:

"It's very little. I'm sorry, but our generation has progressed, we're not like the old days...We say no, I won't just bring anyone [to cut her], I'll take her to a doctor to decide whether she needs it or not...Our generation, compared to our parents' generation has learnt the right from the wrong. Everyone's progressed and our generation is all welleducated"

Mother, IDI, Rural Gharbeya

"No, people now understand and have awareness. Maybe 30 percent or 20 percent are convinced of FGM/C. Look, our generation now understands and knows and is well-read and cultured. At least those who are my age, those who attend community centres and are university-graduates."

Mother, IDI, Urban Gharbeya

Some mothers, believing that abandonment is now the norm, found comfort in abiding to the new status quo and in following the crowd, as illustrated by this mother from rural Gharbeya who admits that her opinion on $\mathrm{FGM} / \mathrm{C}$ was influenced by her community:

"In the matter of not circumcising my girls, yes [my opinion is based on the community around me] because a lot of people now haven't circumcised their daughters, so why would I take a risk?"

Mother, IDI, Rural Gharbeya

\section{Effect of FGM/C on girls' marriageability}

Embedded among the beliefs that have traditionally fuelled support for the continuation of FGM/C is that the practice was considered to ensure girls' marriageability. Given the significance of marriage for Egyptian society (Malmström, 2016), the influence of FGM/C on whether a girl would marry becomes a worthy notion to explore among abandoners. Some participants displayed awareness of the potential influence of $\mathrm{FGM} / \mathrm{C}$ on a girl' marriage potential, as illustrated in the quotes below:

"If they are older women, of course [whether their daughter in-law is circumcised] will matter to them a lot... She'll keep saying, for example, that if her husband leaves her for a bit, she'll go do inappropriate things behind his back, 'No, we don't want this, we want a girl who will be good... the older people want a girl who is 'good' to preserve her husbands' [their sons'] home."

Uncut girl, IDI, Rural Gharbeya

"If there's a potential suitor, his mother might ask [if the girl is circumcised]"

Mother, IDI, Urban Sohag 
However, women often noted that they perceived that FGM/C status had no impact on a woman's marriageability (i.e. that a potential husband and his family should not care if a woman is uncut). Confidence in this counter-traditional view provides significant comfort for Egyptian families in their abandonment decision:

"I think [a suitor] wouldn't know (laughter)... they wouldn't know if a girl is cut of not. I think people's mentality is... no longer ignorant"

$$
\text { Uncut girl, IDI, Rural Gharbeya }
$$

"If the person [that l'm going to marry] is well educated, then it won't make a difference to him [that l'm uncut]. He'd be knowledgeable. But any other normal person, no, they might be like their parents and have their traditional views that the girl must be cut"

$$
\text { Uncut girl, IDI, Cairo }
$$

When questioned about a scenario in which this type of societal order is threatened, where men actually do care whether their wife (or potential wife) is cut, a common coping mechanism among participants was to separate themselves into an 'educated' and cultured band of society and to insist that they will marry within this circle of people, again categorising those who support FGM/C as ignorant. This is illustrated by the following discourse with a young woman from Cairo who insisted that people nowadays are more aware and mature, and that she would not accept an 'ignorant' husband:

"Nowadays people are more aware and more conscious. But in the past, yes of course an uncut girl would have lower chances of marriage... But I would never approve of a, sorry, an ignorant man [as a suitor] ... He'd be mature and aware, and he'd know that [FGM/C] is wrong. And l'd never approve of exposing my future kids to something like this, too!"

$$
\text { Uncut girl, IDI, Cairo }
$$

Some mothers also displayed similar dispositions. When asked whether she would cut her daughter if she was requested to do so by a potential suitor, one Cairo mother strongly refused and insisted she would only marry her daughter to a 'cultured' man:

"I attended a meeting and they were talking about FGM/C. We were ten or eleven people, and they asked us if we'd circumcise our girls. And one of the women said that a man once married a woman and when he found out she wasn't circumcised he sent her to her parents to cut her... I responded by saying that he doesn't deserve her... if this were to happen to me, I wouldn't circumcise her, and l'd divorce her from him. I'm telling you; this matter could've led to divorce between her dad and me if he had insisted that we circumcise her [...]. If her husband requests that she's cut I'll tell him 'come here, did I marry my daughter to someone who doesn't understand, or is stupid?' No, I need to marry her to a cultured man. I have two conditions for her: no circumcision, and that she's married to an educated man."

Mother, IDI, Cairo

\section{Conversations in the private sphere}

Conversations have the power to shape people's opinions and their subsequent decisions on $\mathrm{FGM} / \mathrm{C}$. While some participants noted that it is common to have conversations with close friends, family or neighbours about their abandonment of $F G M / C$, others viewed it as an entirely private matter and feared that exposing their abandonment status may expose them to criticism or external pressure to change their decision.

Within the private sphere, conversations, if present, often happened among close friends, relatives, neighbours, and close work colleagues. This has important implications, concurrent with the spatial analysis of FGM/C, given that people who reside or work in close quarters may influence each other's opinions on FGM/C, or may at least have the potential to stir up mutual reflection and curiosity on the topic: 
"[The family] can talk to no one except neighbours and relatives. Relatives because they're family so they'd need to take their opinion, and neighbours since it's normal, the topic just comes up. And girls can talk together. A girl might say 'my family thinks FGM/C is right' and we'd tell her 'no, it's wrong'... it depends on the people"

Uncut girl, IDI, Rural Sohag

"My colleagues at work and my friends [talk about FGM/C]. For example, a woman might be talking about her daughter, one talking about her sister, another talking about herself... One could say FGM/C was the cause of her divorce"

Mother, IDI, Cairo

Conversations on $\mathrm{FGM} / \mathrm{C}$ sometimes consist of women asking female relatives and close friends if they have had their daughters undergo FGM/C, seeking their opinions before doing so for their daughters. Some abandoning mothers claimed to encourage these inquiring mothers to abandon the practice in their conversations, while some recognised the freedom of others to practice whatever they please on their daughters and exhibited awareness of their inability to convince others of their abandonment stance:

"When a woman is going to circumcise her daughter, she could come to ask me, assuming that I've cut my daughter... She'll ask, 'Who did you take your daughter to?'...So I say no, I didn't circumcise her'

Mother, IDI, Urban Sohag

"There are people who do ask [about FGM/C] ... If someone going to circumcise their daughter, she could come to take my opinion... If I see someone going to get their daughter circumcised, I include myself in the conversation and I tell them my opinion... I ask them why and I get mad when someone does that (circumcises). This could be a friend, a neighbour... I tell them 'No.' If they're convinced, they're convinced, if not then it's fine. It's a personal freedom"

Mother, IDI, Urban Sohag

Some participants, however, indicate that conversations on $\mathrm{FGM} / \mathrm{C}$ within the community are few and rare, more of a taboo and shameful topic that is not tackled in conversation and is left to organised awareness campaigns in the public sphere, and private decision-making within direct families. This view was highlighted by two participants from rural areas:

"No, no. No one's said anything [about my abandonment of FGM/C]. I haven't told anyone at all. In the rural areas we don't like talking about these heavy topics... We consider it shameful. We've heard it all, so everyone's just on their own... No one opens up the topic" Mother, IDI, Rural Gharbeya

"People don't talk about FGM/C outside of the awareness campaigns. Because we're in villages, you know, so they see that this is something inappropriate and that it's shameful to talk about things like this"

Uncut girl, IDI, Rural Sohag

\section{Conversations in the public sphere}

Beyond private conversations within families and between community members, participants mentioned that conversations on $\mathrm{FGM} / \mathrm{C}$ surface within the public sphere in awareness campaigns on television programmes and on social media. These 'public' conversations appeared to reach multiple family members and were often seen as a trustworthy source of information for parents who are making a decision about their daughters, as well as for girls who are formulating their own opinions on FGM/C.

Several mothers and girls mentioned that community-run awareness campaigns and anti-FGM/C advertisements on local television have had a significant influence on their personal opinions on 
FGM/C, including some who decided to abandon the practice and their support for it largely based on the information they received, as illustrated by the quotes below:

'When we sat with others and people were saying 'no' and we discussed it, we decided that's it, we're not circumcising her...They're the ones who told us in the beginning; the community campaigns. We didn't know before that. At home they wanted me to circumcise [my daughter], but when we went out to the community campaigns and church etc, they said 'no'."

Mother, IDI, Rural Sohag

"We used to learn at the community campaigns that [FGM/C] is a harmful practice and they would make us aware that what is right and wrong. They would tell us that [FGM/C] is bad, don't let anyone force you to do anything on your body. Girls become devastated and might get excessive bleeding from it. Before the campaigns, I didn't know it was harmful"

Uncut girl, IDI, Rural Sohag

Participants displayed a large amount of trust in the messaging and authority of these campaigns. For instance, when asked whether there were any benefits to $F G M / C$, one mother in rural Gharbeya, who solely credited television advertising campaigns for the formulation of her opinion, displays complete, unquestioning trust in the authority of their messaging, and says that if there were actually benefits the campaigns would call for continuation of FGM/C instead of abandonment. Another mother in Urban Sohag, trusted the authority of those involved in the antiFGM/C community campaigns:

"No, I've never heard of benefits of FGM/C. Even on television they say 'No to FGM/C. If there were benefits, they would say it. The Ministry of Health would even say to circumcise the girls, but they said no. No to circumcision."

Mother, IDI, Rural Gharbeya

"When we attend a community campaign [...] the people who are there are doctors and people who understand and people who work on violence against women... so they say important things"

Mother, IDI, Urban Sohag

Awareness campaigns also seem to be reaching several family members, including husbands and grandmothers, and influencing their opinions. This is notable due to the extent to which different family members may play either a direct or indirect role in the decision-making process, as highlighted above in the sections on authoritative condemnation and the awareness of other family members of the anti-FGM/C messaging. This is further highlighted in the following quote by a girl from urban Gharbeya whose grandmother, a previous supporter of FGM/C changed her opinion and stopped placing pressure on her mother to have her cut:

"At first, my grandmother would pressure my mother. My grandmother would influence her.... She would say 'we have to do it...' but then she saw around her and they all saw the awareness campaigns- there were campaigns on the streets saying 'No to FGM/C' and television advertisements and stuff, she didn't like [FGM/C] at all anymore"

Uncut girl, IDI, Urban Gharbeya

The role of television as a valuable source of information and in opinion-formulation is not limited to anti-FGM/C advertising campaigns; several participants mentioned the topic of FGM/C being addressed in television series and in films, which depict the negative consequences of $F G M / C$ and those who continue to perform FGM/C in a negative light. This is illustrated in the following quotes:

"I've also heard that there are FGM/C cases that could get excessive bleeding and that there are people who die due to FGM/C. We've heard a lot and watched a lot of series and films that depict FGM/C. A girl is circumcised and suddenly dies, and that's it. Most of it 
honestly is on the television... most of the series and films we used to watch in the past would warn us against FGM/C."

Uncut girl, IDI, Rural Gharbeya

"They depicted the people who do FGM/C as murderers... in television and in stories. They always depict the people who perform it as ignorant people who don't understand what they're doing."

Uncut girl, IDI, Urban Gharbeya

Conversations and campaigns on the internet and social media also surfaced as important sources of information for some participants, especially girls, who claimed that these campaigns helped them formulate their opinions and spread information on the harms of FGM/C:

"My grandmother was the first person to talk to me about FGM/C. And then it appeared on television programmes and then on Facebook and the girls' groups there. They talk about it. When I see a girl who's undergone this, for example a case on television or someone who recounts her experience on Facebook or on social media, I always find that she's unhappy and that, for her, it's a really bad experience. So [my opinion] is based on that "

Uncut girl, IDI, Urban Gharbeya

"There are videos on the internet about the psychological pain and the amount of physical pain a girl goes through due to FGM/C"

Uncut girl, IDI, Urban Sohag

It is not simply organised awareness campaigns that seemed to have influenced women's opinions on FGM/C. 'Conversations' in the public sphere that had the potential to lead to abandonment of FGM/C included the voices of key influential, trusted figures within the community who influenced women and directly changed their minds. For example, one Cairo mother, facing pressure from the female figures (her own mother, her mother in-law and her uncle's wife) within her family, identified her affinity towards the opinion of a well-respected sheikh as the factor which allowed her to withstand familial pressure and formulate her own opinion:

"In the past it would be our family [who would talk about FGM/C]. Like my mother, my mother-in-law and my uncle's wife... [My daughters] were still young, but [my mother] would tell me they have to be circumcised. She told me when your daughter grows up and is 9 or 10 years old, then you should circumcise her. When my mother passed away, and I started listening to Sheikh Sharaawy, I was convinced of his opinion."

Mother, IDI, Cairo

However, findings reveal that there is always a threat that people-even so-called 'abandoners' of FGM/C-are receiving their messaging from multiple, unregulated sources and are thus susceptible to relapsing. For example, this rural Sohag mother who did not have her older daughter (included in this study) undergo FGM/C went on to have her younger daughter cut after facing external pressure, although she regrets it now and blames her actions on receiving contradictory messaging:

"I didn't know [that FGM/C] doesn't have any benefits. Someone would say yes, someone would say no. They were nagging non-stop. You know how the old, traditional folk are."

Mother, IDI, Rural Sohag

Similarly, it is important to note that not all information delivered through the internet and through social media is supportive of the abandonment of FGM/C. While some women have found information about women's traumatic experiences with $\mathrm{FGM} / \mathrm{C}$ on the internet to have helped shape their negative view on FGM/C, others have received mixed messaging. For example, one of the girls from rural Gharbeya had expressed that FGM/C may cause sexual frigidity, but that lack of FGM/C may leave a woman with too much sexual energy, went on to explain how uncut women may use social media to search for sexual relations, and how she personally goes online 
to search for 'both harms and benefits' of FGM/C, illustrating the lack of moderation of the messaging available online:

"I have some colleagues who are circumcised, and some who are not. And I hear about those who are not circumcised; that her husband can't deal with her and that it's a big deal and he can't stand it so they're going to divorce. At the same time, I hear about one who is sexually frigid, and her husband can't stand [sex] with her... He says, 'no I don't feel any feelings with her and don't feel anything towards her, and she's unable to reciprocate any sensations,' and 'No, I can't live with her anymore.' I mean, it's a double-edged sword at the same time... Social media [helped me formulate my opinion]. When you go and search for these things, you'll see this: the harms and the benefits"

Uncut girl, IDI, Rural Gharbeya

Conversations have the power to transform the prevailing opinions on FGM/C and thus are a crucial construct within the abandonment narrative. However, findings demonstrate that the mixedmessaging apparent in both private and public conversations can threaten the sustainability of abandonment efforts, highlighting the importance of ensuring that the predominant narrative on FGM/C within communities is one that supports abandonment of the practice.

\section{Challenges and tensions faced by abandoners within their families or communities and strategies to mitigate the risk of relapse}

In this section, we summarise the findings highlighting the challenges and tensions faced by abandoners. We also summarise the strategies employed by abandoners to mitigate the risk of relapse

\section{Challenges and tensions faced by abandoners}

Findings suggest that abandoners are often aware of traditional views that $F G M / C$ has an impact on a woman's behaviour, though they may not personally adhere to these beliefs themselves. Thus, some abandoners are often highly aware of the critical eye of society's gaze. While participants, particularly mothers, often expressed pride in their abandonment of the practice, some acknowledged the moral shame tied to abandonment and the consequences for the reputation of the family and the uncut girl, and expressed concern about the assumptions that the community might make about a girl's behaviour if they know she's uncut:

"Honestly, no one's tried to get involved. But there was a neighbour who told me not to tell anyone that I haven't had my daughter cut and that she hasn't either because here there is a world of ignorant people so they say for them it could be a scandal that she's uncut[...]"

Mother, IDI, Cairo

"There are no [difficulties] apart from what older people say, those people who aren't enlightened... [The challenge] is just what people say... 'Why is the girl not circumcised?', 'What's wrong with her?', 'Is she not well brought up?', 'Is she deviant?'”

Uncut girl, IDI, Rural Sohag

In Sohag, there were two families (one rural, one urban) who had abandoned the practice for the eldest daughter (the one included in the study), then it was discovered during the IDIs that the parents had performed FGM/C on the girls' younger sisters. In both cases the parents subsequently regretted their decision and claimed that they were against FGM/C, but had cut their younger daughters because of external pressure from others:

"Yes, they were influenced [by what people said] after me... [they changed their mind] because of what people were saying"

Uncut girl, IDI, Urban Sohag

"Yes [others' influenced us] because there was a lot of talk by the older people. But now we recommend to our neighbours and my siblings that they don't circumcise" 
Abandoners frequently mentioned external pressure from community members and family members to perform FGM/C as a challenge they faced. While conversations had the power to foster a space to discuss reasons for abandonment or to recount other's negative experiences of $\mathrm{FGM} / \mathrm{C}$, as discussed earlier, private conversations also represented a space where abandonment could become challenged. Women in the family who supported FGM/C including aunts and grandmothers, were often a source of pressure for abandoning families, trying to persuade abandoners to change their minds or encouraging them to carry out FGM/C:

"[The grandmother] has a huge impact, of course. My grandmother when my mother circumcised my older daughter got very mad and asked her why she did it. [My grandmother] was against FGM/C but my mother got worried about what people say"

Uncut girl, IDI, Urban Sohag

"I was in first preparatory grade (middle school) or so when they said that me and my cousin are close in age and so we both should be [circumcised] together. But mother said no, I'm not going to cut her [...]. My grandmother [wanted to circumcise me] but my mother was persistent on her opinion"

Uncut girl, IDI, Rural Gharbeya

Participants seemed aware of the immense pressure community members can place on one another with regards to the FGM/C decision. Mothers who support FGM/C seemed to try to convince abandoning mothers to circumcise their daughters. One mother from urban Gharbeya, whose own mother did not circumcise her, explained how their neighbour had tried to pressure her mother into performing FGM/C on her and her sisters:

"I heard people telling my mother 'you're not going to circumcise them?' We were two girls so they would tell her, 'oh you're not going to circumcise them' and she would say no... Our neighbor, for example used to tell her, 'Are you not going to circumcise your daughters?' just like she did, and she would say 'No, I'm not doing anything to my girls"

Mother, IDI, Urban Gharbeya

One girl from urban Gharbeya, expressed how, after admitting to not having been cut to a friend's mother, the woman started expressing how her own daughter has undergone FGM/C and is totally fine, and began to nag her, yet that woman's' daughter, having experienced it herself, warned the girl not to do it, displaying the potential mixed messaging that occurs when FGM/C is discussed in an uninhibited environment:

"A while ago a neighbour [asked if I was circumcised] and I said no. She asked me 'why' and I told her because of my parents. So, she told me 'Well my daughters been circumcised and she's totally fine, as you can see.' I told her she must be psychologically devastated. And even her daughter herself told me never to do [FGM/C] ... But people start to nag and they think 'How come this has happened to my girl only? The other girls should also go through the same thing"

$$
\text { Uncut girl, IDI, Urban Gharbeya }
$$

When asked whether families might be forced to have their daughter undergo FGM/C, one girl in Cairo showed awareness of the external pressures faced by abandoning families living in communities where $\mathrm{FGM} / \mathrm{C}$ is the norm:

"If you search, you'll find families [who were pressured into FGM/C] because there are people who cannot handle the social pressure. When you live in a community in which everyone is circumcised [...] sometimes parents fall for this...so that their girl isn't different" 


\section{Mitigation Strategies}

Some participants noted that they mitigated external pressure by pretending that they had not abandoned the practice in order to avoid gossip, and to preserve the girl's- and the family'sreputation (reiterating the idea of 'moral shame', which challenges abandoners). Several mothers admitted to having lied about their daughters' FGM/C status and some girls revealed having been directed by their mothers to pretend that they've undergone FGM/C. As illustrated in the following quotes, this mitigation strategy allows families to uphold their abandonment status while avoiding the external pressure from others to change their stance.

"My neighbours, both the one upstairs and downstairs, would tell me 'we circumcised our daughters, will you not circumcise [yours]?' So, whoever asks me, I just tell them I circumcised her. Because they're convinced that this is right. So, I just cut the conversation so that I don't create noise around myself and my girls... Given that she's done the wrong thing and is convinced by it, if I come to speak with her [about FGM/C], I'll be the 'bad' one. No one knows [about my daughters' lack of FGM/C]. I don't open this topic up with anyone"

Mother, IDI, Cairo

"I told [my uncut friend] that they say that the girls who don't do [FGM/C] aren't good and they say that they do inappropriate things. So, I said, well we're good and we're decent and people compliment us and compliment our parents... I told her that if people know we aren't circumcised they might realise 'Oh, they're well-behaved, they're decent...why are people claiming that if the girl isn't cut she won't be well-behaved?'[...] Personally, [if anyone asks if I'm cut] I just say yes, I'm circumcised. Because people talk a lot and I don't want people to talk... My mother told me [to say this] "

$$
\text { Uncut girl, IDI, Cairo }
$$

For one mother in rural Gharbeya, her ability to withstand pressure within conversations largely depended on her having been given a medical justification that her daughter did not 'need' FGM/C according to a doctor. This medically justified abandonment of the practice seems to give abandoners confidence in their decision and offered a socially approved reason to resist the social pressure to relapse into $\mathrm{FGM} / \mathrm{C}$ :

"My neighbours in our previous house. They'd ask 'was [daughter] not circumcised. I'd say 'no'. 'Why?' they'd ask, and l'd tell them she doesn't have anything, and that I took her to a doctor twice and she doesn't have anything at all'"

$$
\text { Mother, IDI, Rural Gharbeya }
$$

Others maintained their abandonment status by considering $\mathrm{FGM} / \mathrm{C}$ a private, familial matter that others outside the family should not get involved in or know about. This is often done to avoid outside pressure or others' gossip, and for abandoners to maintain what they consider to be their right to privacy:

"Honestly, l've never sat with anyone and talked with them [about FGM/C]. Because this is my personal matter. I won't let anyone into my private matters. This is something that has to do with me and my daughters. No one has the right, close or stranger, neighbour or not, to talk about this thing with me. No one [knows about her lack of FGM/C]. I'm not going to spread this... and no one has the right to ask me about something like this"

Mother, IDI, Cairo

Along similar lines, mitigating the risk of relapse involved dodging the question and saying that they have not abandoned FGM/C, as in the section above on moral shame:

"Yes, [we've talked about FGM/C] a lot. With our older relatives. They'd ask my mother if she'd circumcised us and she wouldn't want to go into details, she'd just say yes. Because the level of thinking of women in the past is different than it is now. She wouldn't comprehend it if you tell her (no). She's used to [FGM/C] and to the old traditions... We're three girls. My mother just says she's circumcised us to avoid the pressure" 
Uncut girl, IDI, Cairo

\section{Discussion}

The overall aim of this study was to understand the characteristics of abandoners, the challenges they have faced in abandoning FGM/C, and factors which may have helped them maintain their abandonment position. Utilising data from the 2014 Demographic Health Survey, abandoners were defined as women who had at least one daughter who was not circumcised and reported that they did not intend to circumcise their daughters in the future. It is important to consider the limitation of this definition in that it is dependent on the mothers' intention to circumcise - which might be skewed since mothers might not want to disclose their true intentions, considering that $\mathrm{FGM} / \mathrm{C}$ is illegal, and that it is also remains a taboo topic. Keeping the limitations of the definition in mind, only $29 \%$ of women aged 15 to 49 were categorised as abandoners of FGM/C. Qualitatively, the study included young uncircumcised women aged between 18 to 24 years old, and the mothers of uncut women of the same age. The decision to limit the sample of young women to age 18 and older was based on the low chances of these women being cut in the future.

In line with Cloward (2016) who argues that the cost of defection from a norm can differ according to the status of the abandoners in the community, their exit options and whether there are temporal shifts in public opinion, such as the presence of highly visible defectors, we found a significant correlation between mother's education, her husband's education, their wealth quantile and the odds of them being abandoners. While this could suggest that the more educated might intrinsically be more convinced of abandonment, another explanation could be that given their elite status within the community, they are less prone to criticism and are more confident in taking the first steps to abandon. In other words, those with certain demographic characteristics could have more exit options and therefore do not need to wait for temporal shift in public opinion and can take the decision to abandon regardless. These pathways cannot be determined from the results of this study and may be worth investigating in further studies.

In the spatial analysis, we found a weak spatial correlation in prevalence rates between different governorates, meaning that nearby governorates do not necessarily have similar prevalence rates. However, looking at smaller administrative (Kism/Markaz) units, there was a strong spatial correlation implying the presence of clusters of abandoners across the country. While socioeconomic and demographic characteristics were significantly associated with the likelihood of women being abandoners, the geographical location of the women also appeared to significantly contribute to this likelihood. In fact, even after accounting for socio-economic differences, geographical proximity to other abandoners appeared to still contribute to the women's likelihood of being an abandoner. Meaning that, while for example being a woman who has completed secondary education, coming from a middle or high wealth quantile or having not been circumcised, would increase the likelihood of this woman being an abandoner regardless of where she lives, the likelihood of her abandoning is also dependent on, or increased by having other abandoners nearby. This does not necessarily confirm Mackie's theory that a significant proportion of the community need to defect together, especially since spatial co-relation differed from one area to another-meaning that this theory cannot be generalised. However, the findings suggest that in some cases, the presence of abandoners living nearby is important for others to start abandoning as well. Indeed, from the qualitative interviews, it was clear that some abandoners felt more comfortable taking the decision not to circumcise because they believed that everyone around them had abandoned the practice. Others, who were not surrounded by abandoners, found comfort in seeing some models of abandoners around them who seemed to be leading healthy lives, and whose reputation has not been tainted by their circumcision status. 
Cloward (2016) argues that within a group where a norm is common, individuals will be punished or rewarded according to whether they comply by it. She refers to the net social costs and benefits experienced by an individual for a given action as the social utility, which must be balanced against an individuals' true attitudes. Just as there is value from sticking to a social norm, there is also value attained from sticking to one's true attitudes and aligning one's public actions with their beliefs. In the case that an individual holds a view which is in contrast to the social norms, they must decide whether to act according to their own views and risk social punishment or to suppress their preferences and go against their beliefs in order to avoid social costs. It is also important to take into consideration, that the extent to which an individual draws value from behaving in a manner consistent with one's attitudes_-referred to as the expressive utility by Kuran (1995) varies from one person to another. Meaning that while for most individuals, acting against one's beliefs brings a level of discomfort, this varies from one person to another.

In this case, we have found that many abandoning mothers decided to defect from FGM/C despite social costs they would have to pay, because they wanted to avoid subjecting their daughters to the negative health and psychological consequences of the practice. Moreover, they believed that circumcision will make their daughters sexually frigid and inhibit them from having healthy sex lives with their future husbands. The importance of sexual libido was mostly tied to the prospect of marriage -in that mothers want their daughters to be sexually satisfied within marriage, either for their own sake, or for the sake of the satisfaction of their husbands and thereby protecting them from an unhealthy relationship with their partners or from divorce. Moreover, some abandoning mothers mentioned that they would not circumcise their daughters because it is against their religious beliefs. The intrinsic utility of abandonment for the mothers-or the value they gain from not circumcising -is in standing their ground when it comes to preserving and protecting their daughters from the physical, psychological and sexual consequences of $F G M / C$, and in abiding by their religious beliefs.

According to the organised diffusion theory, abandonment can be achieved through participants sharing information, persuasion, and debate spread through existing familial and social networks, and it categorises adopters into innovators, early adopters, early majority, later majority, and laggards -depending on their relevant point of uptake of an innovation (Rogers, 1962). Early adopters seemed to face more challenges within their communities. For the most part, though, most participants interviewed during this research seem to part of an early majority-they were not the first ones within their communities to abandon. Although the early majority appeared to have contact to early adopters, which gave them more courage to abandon the practice themselves, they still faced the same challenges in deciding to abandon the practice.

While there seems to be some social status—or social utility—gained by abandoners in seeing and presenting themselves as more educated and progressive than those who circumcise, findings suggest that abandoners still face harsh reputational and tangible costs. For example, abandoning mothers had to choose between following their own beliefs and risking the reputation of their daughters and possibly their marriage prospects. They also had to navigate conflicting information surrounding the topic and stick to their belief that their daughter's behaviour is not linked to her circumcision status despite this being a common belief. Where women were concerned about the association between circumcision and sexual chastity, they appeared to compensate by ensuring that their girls are perceived in the community as well behaved. Further, many of the mothers interviewed appeared to fight back against the social reputational costs of abandonment through associating themselves to an educated, progressive sector of society, while claiming that $F G M / C$ is only performed by the less educated, more traditional individuals within the community. This also provided them with a protection mechanism when asked whether they think that their daughter's marriage prospects are at risk, through claiming that they will only marry off their daughters to educated families who do not believe in FGM/C. Moreover, even if the abandoners did not consider 
themselves as part of an elite, educated sector within the community, they sometimes relied on backing up their opinion with the opinions of those who are well respected within the community. The most obvious form of this is through obtaining a doctor's opinion, as this can help them defend their actions and portray the decision not to circumcise as one that is backed up by a respected, progressive, opinion.

Study findings suggest a significant likelihood of relapse for three key reasons. First, while most abandoning mothers believed that their daughters should be entitled to some sexual satisfaction, either for herself or for the sake of her husband, many still believed that there is a correct amount of sexual libido and energy that a woman should have. The defining argument is how this level should be achieved rather than whether it should be, feeding the idea that there could be a "need" for circumcision. While some participants mentioned that even medicalised FGM/C can be dangerous - meaning that they believed that the practice can have physical and psychological harms even when performed by medical practitioners, some turn to medicalised FGM/C, which is perceived by some as more progressive and less dangerous than more "traditional" forms to regulate their daughters' sexuality in a "safer", more "progressive" manner. Alternatively, for those who still choose not to circumcise, associating circumcision with girls' behaviour could lead to stricter parenting, with increased restrictions on girls' mobility to ensure that daughters remain "well-behaved" despite not being circumcised.

Second, some abandoners did not circumcise their daughters, but retain the belief that there is sometimes a "need" to circumcise, depending on the size of the genitalia, if the girl experiences excessive genital itching, or when the girls exhibit behaviour that show they are not calm, wellbehaved or tame enough. This might also lead to a risk of relapse.

Third, while many mothers recalled the trauma of their own procedures as one of the main reasons behind them not wanting to circumcise their daughters, a few mothers associated the trauma with 'traditional' cutting with one mother, for example, mentioning that her parents spared her the trauma by pursuing a more 'civilised' 'medical' practice. The belief that medicalised FGM/C is acceptable because trauma can be minimised through sedation or painkillers can hinder abandonment moving forward, with future mothers not having the same motivation to protect their daughters from the trauma that they personally experienced.

The sustainability of abandonment also appears to be threatened by the weak personal conviction of the value of abandonment among some abandoners. Specifically, it seems that some abandoners had decided not to circumcise their daughters in order to comply with religious, medical and legal advice - rather than being convinced of its benefits or harms. Abandoners may receive information from multiple sources including religious leaders, doctors, TV advertisements, awareness campaigns, social media and from family and friends. Conflicting messages can pose a threat to the sustainability of abandonment efforts. Although this might point to the need to unify abandonment messages, it can prove to be extremely difficult to do so, as regulating all sources of information, including information spread between family and friends, and social media platforms is not only practically impossible, but furthermore, the content of messaging does not tackle the main issue at hand-that there is no "need" to regulate women sexuality. Most messaging mentioned by study participants, focused on the risks of FGM/C-physically and psychologically - and the stance of religion on the topic. The perception that women's' behaviour and sexuality need to be regulated, remains a common perception that is rarely challenged. 


\section{Limitations}

Study findings should be interpreted in light of the following limitations. First, while testing the instruments in the early stages of the study, we learnt that husbands were unwilling to speak about their wives' circumcision status. There were also concerns about inclusion of husbands creating spousal conflict. As such, although we intended to include husbands and fathers of uncircumcised girls, we were only able to interview three male interviewees across all three governorates and thus could not include their data in the analyses. Second, while the initial plan for the study was to include insights from influential figures within the community, many participants did not mention any specific influential figure that affected their decision within the interviews and focus group discussions. Third, the EDHS (the main quantitative data set used in this study) was conducted in 2014. This is the most recent quantitative data available on the subject. The qualitative data collection, however, was conducted in 2019. There was therefore a gap in time in the collection between the quantitative and qualitative that could impact the results. Fourth, the definition of abandonment in the quantitative analysis-at least one daughter who is not circumcised and not intending to circumcise her-could lead to a misclassification of abandoners especially given the findings from the qualitative component that the definition of $F G M / C$ may vary with some people believing that medicalised cutting is not FGM/C. Finally, social desirability is also a concern, considering that some mothers may not wish to disclose that their daughters have been circumcised, or that they have an intention to circumcise.

\section{Conclusion}

This study set out to understand the characteristics and geographic location of abandoners, the challenges and tensions abandoners face, the factors influencing abandonment and its sustainability, the risk of relapse, and the key reasons behind relapse in FGM/C practice amongst abandoners. Religion, mothers' and fathers' education and wealth status, and the mothers' circumcision status were all associated with the likelihood of a woman being an abandoner. We also found that women within regions close to each other were likely to conform to similar practices with regards to $\mathrm{FGM} / \mathrm{C}$, regardless of their socio-economic and demographic characteristics.

The qualitative results revealed that for abandoners, having role models nearby of girls who have not been circumcised and yet lead happy and healthy lives facilitated the process of abandoning the practice. Moreover, results suggest that for some abandoners, even the perception that FGM/C is not practised, without necessarily having a specific role-model within the community, can make it easier for families to decide not to circumcise.

Mothers mainly abandoned circumcision to protect and preserve their daughters' physical, psychological and sexual health. While they faced societal pressures, including diminishing marriage prospects, and the tarnishing of their daughters' reputation, they responded by associating themselves with a more educated and progressive strand within their community. Nonetheless, we found that even among abandoners, the perceived "need" for circumcisionmainly to regulate girls' and women's sexuality-threatens the sustainability of abandonment in Egypt and may result in an increase in medicalised $\mathrm{FGM} / \mathrm{C}$, which some participants perceived to be an educated, progressive and 'less risky' practice. Results also point to the importance of redefining what exactly $\mathrm{FGM} / \mathrm{C}$ is, as it is apparent from the qualitative data collected that the meaning of abandonment of the practice is not uniform. Some respondents may consider themselves abandoners of the traditional form of $F G M / C$, but still believe that medicalised $F G M / C$ is an acceptable form. Moreover, for some, abandonment of FGM/C was conditional on whether a girl "needs" to be circumcised. For them, abandonment is not necessarily a stand against the practice, but a decision taken according to the needs of each of their daughters. 
It is important to recognise the dangers of the practice even when performed by a medical practitioner. However, more importantly, it is also crucial to start moving the narrative against FGM/C away from the medical harms of the practice to ensure the sustainability of abandonment efforts, and start tackling the root causes of the issue-the belief that women's libido should be regulated and that female genitalia should be of a specific size or form. Moreover, while men's preferences seem to be a factor in pushing some mothers to refrain from circumcising their daughters so that they are not sexually cold, these preferences are not uniform across respondents. It is therefore also important to focus on women's rights to sexual pleasure in and of itself rather than the preferences of husbands/future husbands. 


\section{References}

Achia, T. (2014). Spatial modelling and mapping of female genital mutilation in Kenya. BMC Public Health. 14: 276. https://doi.org/10.1186/1471-2458-14-276

Behrendt, A. and Moritz, S. (2005). Posttraumatic stress disorder and memory problems after female genital mutilation. American Journal of Psychiatry. 162 (5):1000-1002.

Bullen, P. (2012). A multiple case study analysis of the positive deviance approach in community health. Walden University.

http://scholarworks.waldenu.edu/cgi/viewcontent.cgi?article=1019andcontext=hodgkinso

$\underline{\mathrm{n}}$

Cloward, K. (2016) When norms collide: Local responses to activism against female genital mutilation and early marriage. Oxford University Press.

El-Zanaty, F. and Way, A. (2009). Egypt Demographic and Health Survey 2008. Cairo, Egypt: Ministry of Health, El-Zanaty and Associates, and Macro International.

Fahrmeir L. and Lang S. (2001). Bayesian inference for generalised additive mixed models based on Markov random field priors". Applied Statistics. 50: 201-220.

Galal S., Keller, S., Abou Hussein, S., and Wahba N. 2020. Female genital mutilation/cutting decision making process and the role of gender power relations in Egypt. Evidence to End FGM/C: Research to Help Girls and Women Thrive. New York: Population Council.

Ghattass, S., Abdel-Tawab, N. and Abou Hussein, S. (2017) Ending the medicalization of female genital mutilation/cutting in Egypt. http://www.popcouncil.org/uploads/pdfs/2016RH EndMedFGM-Egypt.pdf

Glaser, B. G. \& Strauss, A. L. (1967). The discovery of grounded theory. Chicago: Aldine.

Ismail, S., Abdel-Tawab, N., and Sheira, L., (2015). Health of Egyptian youth in 2014: Knowledge, attitudes and behaviors in panel survey of young people in Egypt 2014: Generating evidence for policy, programs and research. Cairo: Population Council.

Kandala, N. B., Nwakeze, N. and Kandala, S. N. (2009). Spatial distribution of female genital mutilation in Nigeria. The American Society of Tropical Medicine and Hygiene. 81(5): 784-792

Kuran, T. (1995). Private truths, public lies: The social consequences of preference falsification. Cambridge, MA: Harvard University Press.

Lee D. (2013). CARBayes: An R package for Bayesian spatial modeling with conditional autoregressive Priors. Journal of Statistical Software, 55 (13).

Lee D. (2011). A comparison of conditional autoregressive models used in Bayesian disease mapping. Spatial and Spatio-temporal Epidemiology. 2: 79-89.

Leroux B., Lei X. and Breslow N. (2000). Estimation of disease rates in small areas: a new mixed model for spatial dependence." In M Halloran, D Berry (eds.), Statistical models in epidemiology, the environment and clinical trials, pp. 179-191. Springer-Verlag, New York.

Lionello, A. M. (2015). Female genital mutilation in Sierra Leone: A phenomenological study of the experience of abandonment. Doctoral dissertation, The Chicago School of Professional Psychology. 
Mackie, G. and LeJeune J. (2009). Social dynamics of abandonment of harmful practices: A new look at the theory. Innocenti Working Paper No. 2009-06. Special Series on Social Norms and Harmful Practices. Florence: UNICEF Innocenti Research Centre. http://www.unicefirc.org/publications $/ 558$

Mackie, G. (2000). Female genital cutting: The beginning of the end. In Female "circumcision" in Africa: Culture, controversy, and change, edited by Bettina Shell-Duncan and Ylva Hernlund, 253-80. Boulder, CO: Lynne Rienner.

MacNab Y. (2003) Hierarchical Bayesian modelling of spatially correlated health service outcome and utilization rates. Biometrics. 59: 305-16.

Malmström, M.F. (2016). The Politics of Female Circumcision in Egypt: Gender, Sexuality and the Construction of Identity (Library of Modern Middle East Studies). London•New York: I.B. Tauris. Retrieved January 28, 2020, from http://dx.doi.org/10.5040/9781350989139

Mann H. B. and Whitney D. R. (1947). "On a test of whether one of two random variables is stochastically larger than the Other". Annals of Mathematical Statistics. 18 (1): 50-60.

Ministry of Health and Population [Egypt], El-Zanaty and Associates [Egypt], and ICF International. 2015a. Egypt Demographic and Health Survey 2014. Cairo, Egypt and Rockville, Maryland, USA: Ministry of Health and Population and ICF International.

Ministry of Health and Population [Egypt], El-Zanaty and Associates [Egypt], and ICF International. 2015b. Egypt Health Issues Survey 2015. Cairo, Egypt and Rockville, Maryland, USA: Ministry of Health and Population and ICF International.

Modrek S. and Sieverding M (2016) Mother, daughter, doctor: Medical professionals and mothers' decision making about female genital cutting in Egypt. International Perspectives on Sexual and Reproductive Health. 42 (2): 81-92

Moran P. A. P. (1950). Notes on continuous stochastic phenomena. Biometrika. 37 (1): 17-23.

Naguib, K. (2010). The Effects of social interactions on female genital mutilation: Evidence from Egypt. Boston University. http://www.bu.edu/econ/files/2010/05/se fgm egypt.pdf

Population Council (2008). Female Genital Mutilation Abandonment Program: Evaluation summary report. https://www.unicef.org/evaldatabase/files/EGY FGM AP report.pdf

Pearson K. (2009). "On the criterion that a given system of deviations from the probable in the case of a correlated system of variables is such that it can be reasonably supposed to have arisen from random sampling". Philosophical Magazine. Series 5.50 (302): 157175.

Rogers, E. M. (1962). Diffusion of innovations (1st ed.). New York: Free Press of Glencoe.

Spiegelhalter D. J, Best N. G., Carlin B. P. and Van der Line A. (2002). Bayesian measures of model complexity and fit. Journal of the Royal Statistical Society, Series B. 64 (4): 583639

Strauss, A. \& Corbin, J. (1990). Basics of qualitative research. Newbury Park, CA. Sage.

World Health Organization (WHO). (2010). Female genital mutilation (Fact Sheet \#241). http://www.who.int/mediacentre/factsheets/fs241/en/index.html. Accessed Nov 3, 2017 


\section{Appendix}

\section{CAR Model Assumption and Specification}

We assumed that the response variable has a Bernoulli distribution with unknown probability $p$ that the woman is FGM/C abandoner. That is, $Y_{i k} \sim \operatorname{Ber}\left(\pi_{i k}\right)$ and the probability of a woman $i$ aged $15-49$ years being an abandoner in area $k, \pi_{i k}$, satisfies the model:

$\pi_{i k}=P\left(y_{i k=1}\right)=\frac{1}{1+\exp \left\{-\left[\boldsymbol{X}_{i k}^{\top} \boldsymbol{\beta}+f\left(a g e_{i k}\right)+\psi_{i k}\right]\right\}}$,

which can be expressed equivalently using the logit link function as follows:

$\log \left(\frac{\pi_{i k}}{1-\pi_{i k}}\right)=\eta_{i k}=\boldsymbol{X}_{i k}^{\top} \boldsymbol{\beta}+f\left(\right.$ age $\left._{i k}\right)+\psi_{i k}$

where $\boldsymbol{X}_{i k}$ is the vector of categorical covariates such as place of residence and education that corresponds to the $i^{\text {th }}$ woman in areas $k$ and $\boldsymbol{\beta}$ is the vector of coefficients reflecting the effect of those variables on determining whether the woman is abandoner or not. Whereas, $f($.$) is a non-$ linear smoothed effect of the woman's age fitted using a natural cubic splines. The spatial and individual variations across the region denoted by the term $\psi_{i k}$ are modelled by the decomposition: $\psi_{i k}=\phi_{k}+\epsilon_{i k}$,

such that

$\phi_{k} \mid \boldsymbol{\phi}_{-k} \sim N\left(\frac{\rho \sum_{k^{\prime}=1}^{K} w_{k k^{\prime}} \phi_{k}}{\rho \sum_{k^{\prime}=1}^{K} w_{k k^{\prime}}+1-\rho}, \frac{\tau^{2}}{\rho \sum_{k^{\prime}=1}^{K} w_{k k^{\prime}}+1-\rho}\right)$ and $\epsilon_{i k} \sim N\left(0, \sigma^{2}\right)$. (3)

The spatial variation at the area level is modelled by a single set of random effects $\phi=$ $\left(\phi_{1}, \ldots, \phi_{k}\right)$, which is common to all individuals within each area (i.e. individuals within the same area share the same effect) and is modelled by the CAR prior (see Equation 3) proposed by Leroux et al. (2000). In this CAR prior, $\phi_{k}$ has a conditional expectation that is based on a weighted average of both the independent random effects and the spatially structured random effects, where the weight is equal to $\rho$. The weight parameter $\rho$ controls the strength of spatial dependence between the random effects by taking values in the unit interval; with $\rho=0$ in case of spatial independence and $\rho$ close to 1 in case of strong spatial dependence. This CAR model proposed by Leroux et al. (2000) allows the strength of spatial autocorrelation to vary over the space using the set $\boldsymbol{\phi}$ of random effects and the neighbourhood structure defined by the matrix $\boldsymbol{W}$. The matrix $\boldsymbol{W}$ is binary $K \times K$ neighbourhood matrix with entries $w_{k k^{\prime}}$; such that $w_{k k^{\prime}}=1$ if areal units $\left(S_{k}\right.$, $S_{k^{\prime}}$ ) share a common border and 0 otherwise. If two areas are defined to be neighbours their random effects are correlated, while random effects in non-neighbouring areas are modelled as being conditionally independent given the remaining elements of $\boldsymbol{\phi}$.

The second term $\epsilon_{i k}$ is a random effect allowing for individual-level variation across areas, which is given an independent and identically distributed zero-mean Gaussian prior with a constant variance $\sigma^{2}$. This term can be ignored, which is the case here, if no information is available about such dependence structure between individuals except that individuals within the same area are likely to share the same random effect $\phi_{k}$. 
This two-level hierarchical spatial generalised mixed model is fitted in a Bayesian framework as suggested in Fahrmeir and Lang (2001) using the CARBayes package in $\mathrm{R}$ which enables Bayesian inference based on Markov chain Monte Carlo simulation techniques (Lee, 2013). A Uniform $(0,1)$ prior was used for $\rho$ and an Inverse-Gamma $(a=1, b=0.01)$ prior was assigned to the variance $\tau^{2}$. Although the model and its estimation process seem complex, the estimated posterior ORs could be interpreted as similar to those of ordinary logistic regression models. 